\title{
Direct measurements of unimolecular and bimolecular reaction kinetics of the Criegee intermediate $\left(\mathrm{CH}_{3}\right)_{2} \mathrm{COO}$
}

Rabi Chhantyal-Pun, ${ }^{1}$ Oliver Welz, ${ }^{2}$ John D. Savee, ${ }^{2}$ Arkke J. Eskola, ${ }^{2}$ Edmond P. F. Lee,,${ }^{3,4}$ Lucy Blacker, ${ }^{1}$ Henry R. Hill, ${ }^{1}$ Matilda Ashcroft, ${ }^{1}$ M. Anwar H. Khan, ${ }^{1}$ Guy C. Lloyd-Jones, ${ }^{1 \dagger}$ Louise Evans, ${ }^{1}$ Brandon Rotavera, ${ }^{2}$ Haifeng Huang, ${ }^{2}$ David L. Osborn, ${ }^{2}$ Daniel K. W. Mok, ${ }^{5}$ John M. Dyke, ${ }^{4}$ Dudley E. Shallcross, ${ }^{1}$ Carl J. Percival,${ }^{5}$ Andrew J. Orr-Ewing,,${ }^{1, *}$ and Craig A. Taatjes ${ }^{2, *}$

${ }^{1}$ School of Chemistry, The University of Bristol, Cantock's Close BS8 1TS, UK; ${ }^{2}$ Combustion Research Facility, Mail Stop 9055, Sandia National Laboratories, Livermore, California 94551-0969 USA; ${ }^{3}$ School of Chemistry, University of Southampton, Highfield, Southampton SO17 1BJ, UK; ${ }^{4}$ Department of Applied Biology and Chemical Technology, The Hong Kong Polytechnic University, Hung Hom, Hong Kong; ${ }^{5}$ The Centre for Atmospheric Science, The School of Earth, Atmospheric and Environmental Science, The University of Manchester, Simon Building, Brunswick Street, Manchester, M13 9PL, UK. ${ }^{\dagger}$ Now at School of Chemistry, University of Edinburgh, EH9 3FJ, UK

\begin{abstract}
The Criegee intermediate acetone oxide, $\left(\mathrm{CH}_{3}\right)_{2} \mathrm{COO}$, is formed by laser photolysis of 2,2diiodopropane in the presence of $\mathrm{O}_{2}$ and characterized by synchrotron photoionization mass spectrometry and by cavity ringdown ultraviolet absorption spectroscopy. The rate coefficient of the reaction of the Criegee intermediate with $\mathrm{SO}_{2}$ was measured using photoionization mass spectrometry and pseudo-first order methods to be $(7.3 \pm 0.5) \times 10^{-11} \mathrm{~cm}^{3} \mathrm{~s}^{-1}$ at $298 \mathrm{~K}$ and 4 Torr and $(1.5 \pm 0.5) \times$ $10^{-10} \mathrm{~cm}^{3} \mathrm{~s}^{-1}$ at $298 \mathrm{~K}$ and 10 Torr (He buffer). These values are similar to directly measured rate coefficients of anti- $\mathrm{CH}_{3} \mathrm{CHOO}$ with $\mathrm{SO}_{2}$, and in good agreement with recent $\mathrm{UV}$ absorption measurements. The measurement of this reaction at $293 \mathrm{~K}$ and slightly higher pressures (between 10 Torr and 100 Torr) in $\mathrm{N}_{2}$ from cavity ringdown decay of the ultraviolet absorption of $\left(\mathrm{CH}_{3}\right)_{2} \mathrm{COO}$ yielded even larger rate coefficients, in the range $(1.84 \pm 0.12) \times 10^{-10}$ to $(2.29 \pm 0.08) \times 10^{-10} \mathrm{~cm}^{3} \mathrm{~s}^{-1}$. Photoionization mass spectrometry measurements with deuterated acetone oxide at 4 Torr show an inverse deuterium kinetic isotope effect, $k_{\mathrm{H}} / k_{\mathrm{D}}=(0.53 \pm 0.06)$, for reactions with $\mathrm{SO}_{2}$, which may be consistent with recent suggestions that the formation of an association complex affects the rate coefficient. The reaction of $\left(\mathrm{CD}_{3}\right)_{2} \mathrm{COO}$ with $\mathrm{NO}_{2}$ has a rate coefficient at $298 \mathrm{~K}$ and 4 Torr of $(2.1 \pm$ $0.5) \times 10^{-12} \mathrm{~cm}^{3} \mathrm{~s}^{-1}$ (measured with photoionization mass spectrometry), again similar to the reaction of anti- $\mathrm{CH}_{3} \mathrm{CHOO}$ with $\mathrm{NO}_{2}$. Cavity ringdown measurements of the acetone oxide removal without added reagents display a combination of first- and second-order decay kinetics, which can be deconvolved to derive values for both the self-reaction of $\left(\mathrm{CH}_{3}\right)_{2} \mathrm{COO}$ and its unimolecular thermal decay. The inferred unimolecular decay rate coefficient at $293 \mathrm{~K}$, $(305 \pm 70) \mathrm{s}^{-1}$, is similar to determinations from ozonolysis. The present measurements confirm the large rate coefficient for reaction of $\left(\mathrm{CH}_{3}\right)_{2} \mathrm{COO}$ with $\mathrm{SO}_{2}$ and the small rate coefficient for its reaction with water. Product measurements of the reactions of $\left(\mathrm{CH}_{3}\right)_{2} \mathrm{COO}$ with $\mathrm{NO}_{2}$ and with $\mathrm{SO}_{2}$ suggest that these reactions may facilitate isomerization to 2-hydroperoxypropene, possibly by subsequent reactions of association products.
\end{abstract}




\section{Introduction}

Carbonyl oxides, often known as Criegee intermediates, are formed in ozonolysis of alkenes ${ }^{1}$ and are important tropospheric oxidants..$^{2-3}$ The reaction kinetics of carbonyl oxides has been the subject of increasingly intense study ${ }^{4-6}$ since the discovery that carbonyl oxides can be easily prepared via the reactions of $\alpha$-iodoalkyl radicals with $\mathrm{O}_{2}{ }^{7-8}$ The reactions of the simplest carbonyl oxide, $\mathrm{CH}_{2} \mathrm{OO}$, have been most extensively investigated. Carbonyl oxides generally display rapid self-reaction ${ }^{9-11}$ and facile reactions with $\mathrm{SO}_{2}{ }^{5,8,11-15}$ and acids, ${ }^{16-18}$ and somewhat less rapid reactions with $\mathrm{NO}_{2}{ }^{7-8,15}, 19$ Acetaldehyde oxide, $\mathrm{CH}_{3} \mathrm{CHOO}$, shows significant conformer dependence of its reactivity, particularly with water, ${ }^{8,20}$ for which the anti- conformer reacts orders of magnitude more rapidly than does the syn- conformer.

Most recently, the dimethyl substituted Criegee intermediate, $\left(\mathrm{CH}_{3}\right)_{2} \mathrm{COO}$ (acetone oxide) has gained attention as a potentially important tropospheric oxidant of $\mathrm{SO}_{2}$ because it reacts rapidly with $\mathrm{SO}_{2}$ but slowly with water and water dimer, ${ }^{12}$ implying that for similar source strengths it will reach higher steady-state concentrations than Criegee intermediates that react more readily with water. ${ }^{21}$ Acetone oxide can be produced in ozonolysis of branched alkenes, and its behavior may be representative of other disubstituted Criegee intermediates.

In the present work we employ both cavity ring down detection ${ }^{11}$ and photoionization mass spectrometry detection ${ }^{7-8}$ to interrogate kinetics of acetone oxide. Acetone oxide is produced by photolysis of 2,2-diiodopropane $\left(\left(\mathrm{CH}_{3}\right)_{2} \mathrm{CI}_{2}\right)$ in the presence of $\mathrm{O}_{2}$; the formation of $\left(\mathrm{CH}_{3}\right)_{2} \mathrm{COO}$ in this system has previously been characterized by the Lester ${ }^{22}$ and $\operatorname{Lin}^{12}$ groups. Here we describe measurements of rate coefficients for its unimolecular reaction, self-reaction, and reactions with $\mathrm{SO}_{2}$ and $\mathrm{NO}_{2}$.

\section{Methods}

Cavity ring down experiments. The cavity ring down experiment at the University of Bristol has been described in detail previously. ${ }^{11}$ Therefore, only a brief description is provided here. Visible radiation generated by a Nd:YAG pumped dye laser was frequency doubled to obtain $355 \mathrm{~nm}$ radiation which was used to probe the $\left(\mathrm{CH}_{3}\right)_{2} \mathrm{COO}$ Criegee intermediate via its strong $\widetilde{\mathrm{B}}{ }^{1} \mathrm{~A}^{\prime} \leftarrow$ $\widetilde{\mathrm{X}}{ }^{1} \mathrm{~A}^{\prime}$ transition by CRDS. The ring-down time was typically around $5 \mu \mathrm{s}$, which is much shorter than the kinetic decay times being measured. Spectral interferences from different possible chemical species generated in the reaction like $\mathrm{IO}, \mathrm{ICH}_{2} \mathrm{O}_{2}$ and $\left(\mathrm{CH}_{3}\right)_{2} \mathrm{CO}$ are minimal at $355 \mathrm{~nm}$. The cavity ring down signal was measured by a photodiode detector and digitized using an 8-bit oscilloscope. $\left(\mathrm{CH}_{3}\right)_{2} \mathrm{COO}$ was generated in the middle of the cavity by $355 \mathrm{~nm}$ photolysis of $\left(\mathrm{CH}_{3}\right)_{2} \mathrm{CI}_{2}$ in the presence of $\mathrm{O}_{2}$ using the third harmonic of another Nd:YAG laser. Flows of the $\left(\mathrm{CH}_{3}\right)_{2} \mathrm{CI}_{2} / \mathrm{N}_{2}$ premix, $\mathrm{SO}_{2} / \mathrm{N}_{2}$ premix, $\mathrm{O}_{2}$ and $\mathrm{N}_{2}$ into the flow tube were controlled by calibrated mass flow controllers. Time-resolved traces of the $\left(\mathrm{CH}_{3}\right)_{2} \mathrm{COO}$ signal were obtained by varying the time delay between the photolysis and probe lasers, with timings controlled by a digital delay generator. Photolysis-laser-off signals were subtracted from photolysis-laser-on signals at each time delay to obtain background-free kinetic traces. All measurements were performed at a laboratory temperature of $293 \mathrm{~K}$, and at $2 \mathrm{~Hz}$ laser repetition rate, with 1 to 3 laser shots averaged to obtain sufficient signal-to-noise ratios on the kinetic traces.

Photoionization mass spectrometry experiments. The multiplexed photoionization mass spectrometry apparatus has been employed in previous investigations of the kinetics of carbonyl oxides. ${ }^{7-8,17}$ In these experiments, reactions are initiated by excimer laser photolysis ( $351 \mathrm{~nm}$ or 248 $\mathrm{nm})$ of $\left(\mathrm{CH}_{3}\right)_{2} \mathrm{CI}_{2}$ or $\left(\mathrm{CD}_{3}\right)_{2} \mathrm{CI}_{2}$ in the presence of $\mathrm{O}_{2}$ and the composition of the reacting mixture is continuously sampled through a small orifice in the reactor wall. The effusing gas forms a molecular 
beam, which is analyzed by photoionization mass spectrometry, employing an orthogonal pulsedextraction time-of-flight mass spectrometer. The photolysis laser operates at a low enough repetition rate $(4 \mathrm{~Hz}$ or $10 \mathrm{~Hz})$ to ensure that the reaction mixture is completely refreshed between photolysis pulses. Mass spectra are acquired at $50 \mathrm{kHz}$, giving a complete mass profile every $20 \mu \mathrm{s}$. The ionizing photons are supplied by tunable synchrotron radiation from the Chemical Dynamics Beamline (9.0.2) of the Advanced Light Source at Lawrence Berkeley National Laboratory. The tunable photon source allows photoionization spectra that can identify and discriminate isomeric species.

Quantum chemistry calculations of energy surfaces for reactions 1 and 2. The primary interest of our calculations is in spectral identification of $\left(\mathrm{CH}_{3}\right)_{2} \mathrm{COO}$ and its production by reaction of $\left(\mathrm{CH}_{3}\right)_{2} \mathrm{CI}$ $+\mathrm{O}_{2}$. Other isomers of $\left(\mathrm{CH}_{3}\right)_{2} \mathrm{COO}$ have also been investigated, as they may also be formed in reactions associated with the formation of $\left(\mathrm{CH}_{3}\right)_{2} \mathrm{COO}$, and hence may be present in observed photoionization mass spectra. These isomers of $\left(\mathrm{CH}_{3}\right)_{2} \mathrm{COO}$ include 2-hydroperoxypropene $\left(\mathrm{CH}_{2}=\mathrm{C}\left(\mathrm{CH}_{3}\right) \mathrm{OOH}\right), 3$-methyl-1,2-dioxetane and dimethyl-dioxirane. No experimental information is available on their ionization energies (IEs) or their photoelectron spectra. Calculations performed in the present study include density functional theory (DFT), ab initio and Franck-Condon factor (FCF) calculations, which are outlined below and described in detail in the supporting information.

Geometry optimization and harmonic vibrational frequency calculations were carried out on the ground electronic state $\left(\tilde{X}^{1} \mathrm{~A}^{\prime}\right)$ of $\left(\mathrm{CH}_{3}\right)_{2} \mathrm{COO}$ and the two lowest electronic states $\left({ }^{2} \mathrm{~A}^{\prime \prime}\right.$ and $\left.{ }^{2} \mathrm{~A}^{\prime}\right)$ of its cation employing the B3LYP and M06-2X functionals, with the 6-311++G** and aug-cc-pVDZ basis sets, respectively. These DFT calculations were performed using GAUSSIAN09. ${ }^{23}$ Higher level $a b$ initio energy calculations were then carried out at the B3LYP/6-311++G** geometries employing the explicit correlation methods, RHF/UCCSD(T)-F12x, $\mathrm{x}=\mathrm{a}$ or $\mathrm{b}$, as implemented in MOLPRO2012, ${ }^{24}$ with $1 / \mathrm{X}^{3}$ basis set extrapolation to the $\operatorname{UCCSD}(\mathrm{T})-\mathrm{F} 12 \mathrm{x} / \mathrm{CBS}$ (complete basis set limit) value. FCFs between the $\tilde{X}^{1} A^{\prime}$ state of $\left(\mathrm{CH}_{3}\right)_{2} \mathrm{COO}$ and the two lowest electronic states, ${ }^{2} \mathrm{~A}^{\prime \prime}$ and ${ }^{2} \mathrm{~A}^{\prime}$, of its cation were computed within the harmonic oscillator model, with allowance for Duschinsky rotation, using the EZSPECTRUM code. ${ }^{25}$ The two sets of geometries, harmonic vibrational frequencies and normal mode vectors obtained at the B3LYP/6-311++G** and M06-2X/aug-cc-pVDZ levels were used in the FCF calculations.

Similar calculations were carried out for the $\mathrm{CH}_{2}=\mathrm{C}\left(\mathrm{CH}_{3}\right) \mathrm{OOH}$, 3-methyl-1,2-dioxetane and dimethyl-dioxirane isomers of $\left(\mathrm{CH}_{3}\right)_{2} \mathrm{COO}$ (and their cations). For the dimethyl-dioxirane cations, low-lying cationic states were investigated at the M06-2X/6-311++G**, TD-B3LYP/6-311++G** and CASSCF $(8,8) / N E V P T 2 / a u g-c c-p V D Z$ levels, in order to establish the ground cationic state. TDB3LYP calculations were performed using GAUSSIAN09, ${ }^{23}$ while CASSCF/NEVPT2 calculations used MOLPRO2012. ${ }^{24}$

For the reactions to form $\left(\mathrm{CH}_{3}\right)_{2} \mathrm{COO}$ from $\left(\mathrm{CH}_{3}\right)_{2} \mathrm{CI}+\mathrm{O}_{2}$, i.e.

$$
\begin{aligned}
& \left(\mathrm{CH}_{3}\right)_{2} \mathrm{CI}+\mathrm{O}_{2} \rightarrow\left(\mathrm{CH}_{3}\right)_{2} \mathrm{CIOO} \\
& \left(\mathrm{CH}_{3}\right)_{2} \mathrm{CIOO} \rightarrow\left(\mathrm{CH}_{3}\right)_{2} \mathrm{COO}+\mathrm{I}
\end{aligned}
$$

the geometry optimization of reactants and products, transition state (TS) search, intrinsic reaction coordinate (IRC) path (or minimum energy path, MEP) and associated harmonic vibrational frequency calculations were carried out using the M06-2X functional with GAUSSIAN09. ${ }^{23}$ Aug-ccpVDZ basis sets were employed for $\mathrm{C}, \mathrm{O}$ and $\mathrm{H}$, while the aug-cc-pVDZ-PP basis set and associated fully relativistic ECP28MDF effective core potential (ECP) were used, for I. ${ }^{26}$ The M06-2X functional was chosen, because it has been shown to perform well in locating TS geometries, ${ }^{27}$ and is successful in describing analogous reactions involving $\mathrm{CH}_{2} \mathrm{OO} .{ }^{28}$ Higher level ab initio energy 
calculations were carried out at M06-2X stationary points on the reaction energy surfaces, using MOLPRO2012 $2^{24}$ (see supporting information for details).

The permanent dipole moments of various Criegee intermediates, calculated using the GAUSSIAN09 program, were used to calculate the dipole capture limit values for their self-reaction rate coefficients. The ground states of $\mathrm{CH}_{2} \mathrm{OO}, \mathrm{CH}_{3} \mathrm{CHOO}$ and $\left(\mathrm{CH}_{3}\right)_{2} \mathrm{COO}$ Criegee intermediates were optimized at the B3LYP/6-31+G(d) level of theory. ${ }^{23}$ Vibrational frequency calculations were also performed for these geometries at the same level of theory to confirm a stable minimum. Calculations were performed for both syn- and anti- conformers of $\mathrm{CH}_{3} \mathrm{CHOO}$. These optimized geometries were then used to obtain ground state permanent dipole moment values at the CCSD(T)/aug-cc-pvtz level of theory.

Ground state $0 \mathrm{~K}$ energies of $\mathrm{CH}_{2} \mathrm{OO},\left(\mathrm{CH}_{3}\right)_{2} \mathrm{COO}, \mathrm{H}_{2} \mathrm{CO},\left(\mathrm{CH}_{3}\right)_{2} \mathrm{CO}$ and $\mathrm{O}_{2}\left({ }^{1} \Delta_{\mathrm{g}}\right)$ were calculated at the CBS-QB3 and G4 levels of theory using the GAUSSIAN09 program. ${ }^{23}$ These energies were used to calculate exothermicities of the Criegee intermediate self-reaction leading to formation of a carbonyl and oxygen molecules.

\section{Results and Discussion}

\section{Formation of $\left(\mathrm{CH}_{3}\right)_{2} \mathrm{COO}$}

Photoionization measurements. Figure 1 shows the photoionization spectrum of the $\mathrm{m} / z=74$ product observed following photolysis of 2,2-diiodopropane in the presence of $\mathrm{O}_{2}$. The spectrum is compared with the calculated spectra for the various isomers of $\left(\mathrm{CH}_{3}\right)_{2} \mathrm{COO}$ obtained by integration over the Franck-Condon envelopes described above. Both the Franck-Condon envelope and the ionization energy of 2-hydroperoxypropene are rather similar to those of acetone oxide. This similarity prevents secure assignment of the product on the simple basis of photoionization spectra. Formation of 2-hydroperoxypropene may occur in these experiments, although the reaction of 2iodoprop-2-yl with $\mathrm{O}_{2}$ requires intramolecular transfer of an $\mathrm{H}$ atom to connect to 2hydroperoxypropene products. Experiments by Liu et al. ${ }^{29}$ have characterized the formation of $\mathrm{OH}$ radicals after excitation of $\left(\mathrm{CH}_{3}\right)_{2} \mathrm{COO}$ in the $\mathrm{CH}$ overtone region, a reaction that proceeds through the formation of a 2-hydroperoxypropene intermediate. These experiments suggested an upper limit of 16 $\mathrm{kcal} \mathrm{mol}^{-1}$ for the energetic barrier to isomerization from acetone oxide to 2-hydroperoxypropene. Because the reaction of 2-iodoprop-2-yl with $\mathrm{O}_{2}$ to produce acetone oxide and I atom is $14.8 \mathrm{kcal}$ $\mathrm{mol}^{-1}$ exothermic (vide infra), the fraction of initially formed $\left(\mathrm{CH}_{3}\right)_{2} \mathrm{COO}$ with enough energy to isomerize may not be negligible. The 2-hydroperoxypropene isomer is expected to be considerably less reactive than the acetone oxide, and in the kinetics traces of $\mathrm{m} / \mathrm{z}=74$ signal vs. time, a non-zero long-time background is observed after the main portion of the signal decays. This persistent $\mathrm{m} / \mathrm{z}=74$ product may include 2-hydroperoxypropene, as discussed below. Detailed analysis of possible isomerization pathways and products will be given in a separate publication. ${ }^{30}$

Franck-Condon calculations assume continuum ionization to the ground state of the cation, and may not capture the photoionization spectrum accurately if autoionization dominates, ionization to other cation states is important, or other non-radiative processes (e.g., photodissociation, internal conversion) are significant. A fit of the sum of the Franck-Condon envelopes for ionization to the two lowest states of the $\left(\mathrm{CH}_{3}\right)_{2} \mathrm{COO}^{+}$ion to the transient $\mathrm{m} / \mathrm{z}=74$ signal (shown as the solid blue line in Figure 1) agrees well up to about $9.5 \mathrm{eV}$, above which some other component may contribute, for example methyldioxetane (see also the section on $\mathbf{C}_{3} \mathbf{H}_{6} \mathbf{O}_{2}$ isomeric products from reactions of $\left(\mathbf{C H}_{3}\right)_{2} \mathbf{C O O}$ below). Kinetic traces (i.e., $\mathrm{m} / z=74$ signal vs. time) taken at photon energies between 9 $\mathrm{eV}$ and $10.5 \mathrm{eV}$ show the same decay of the initial signal but different amounts of long-time background. 


\section{Franck-Condon factors for Photoionization}

\section{The $\widetilde{\mathrm{X}}^{1} \mathbf{A}^{\prime}$ state of $\left(\mathrm{CH}_{3}\right)_{2} \mathrm{COO}$ and the $\widetilde{\mathrm{X}}^{2} \mathbf{A}^{\prime \prime}$ and $\widetilde{\mathrm{A}}^{2} \mathbf{A}^{\prime}$ states of $\left(\mathrm{CH}_{3}\right)_{2} \mathrm{COO}^{+}$Optimized}

geometrical parameters, computed harmonic vibrational frequencies and ionization energies (adiabatic and vertical, AIE and VIE) obtained at the B3LYP/6-311++G** and M06-2X/AUG-CC-PVDZ levels of calculation are summarized in Table $\mathrm{S} 1$ of the supporting information. Computed relative electronic energies obtained at higher ab initio levels are given in Table S2. Although the two lowest cationic states are quite close in energy $\left(\mathrm{AIE}_{0}(=\mathrm{AIE}+\Delta \mathrm{ZPE})\right)$ values differed by $0.18 \mathrm{eV}$ or $\sim 4.2$ $\mathrm{kcal} \mathrm{mol}^{-1}$; Table S2), the computed energies (Tables S1 and S2) consistently show that the $(1)^{2} \mathrm{~A}^{\prime \prime}$ state is the ground electronic state, similar to $\mathrm{CH}_{3} \mathrm{CHOO}^{+}\left(\widetilde{\mathrm{X}}^{2} \mathrm{~A}^{\prime \prime}\right.$ lower than $\widetilde{\mathrm{A}}^{2} \mathrm{~A}^{\prime}$ by $2.2 \mathrm{kcal} \mathrm{mol}^{-1}$ for syn- and $4.0 \mathrm{kcal} \mathrm{mol}^{-1}$ for anti-). ${ }^{8}$ For $\mathrm{CH}_{2} \mathrm{OO}^{+}$, the cation of the lightest Criegee intermediate, the two lowest states have almost identical energies. ${ }^{28}$ At the highest level of calculation, the best computed adiabatic ionization energies, $\mathrm{AIE}_{0}$ (see Table $\mathrm{S} 2$ ), to the $\widetilde{\mathrm{X}}^{2} \mathrm{~A}^{\prime \prime}$ and $\widetilde{\mathrm{A}}^{2} \mathrm{~A}^{\prime}$ states of $\left(\mathrm{CH}_{3}\right)_{2} \mathrm{COO}^{+}$are $8.79 \mathrm{eV}$ and $8.97 \mathrm{eV}$, respectively. The corresponding, best computed VIE values of 8.93 and $9.01 \mathrm{eV}$ as shown in Table S2 suggest that the ionization band to the $\widetilde{\mathrm{X}}^{2} \mathrm{~A}$ " state would be slightly broader than that to the $\widetilde{\mathrm{A}}^{2} \mathrm{~A}^{\prime}$ state. In fact, for the latter band, the AIE and VIE values differ by only $0.04 \mathrm{eV}$.

Computed FCFs for the ionizations from the $\widetilde{\mathrm{X}}^{1} \mathrm{~A}^{\prime}$ state of $\left(\mathrm{CH}_{3}\right)_{2} \mathrm{COO}$ to the $\widetilde{\mathrm{X}}^{2} \mathrm{~A}^{\prime \prime}$ and $\widetilde{\mathrm{A}}^{2} \mathrm{~A}^{\prime}$ states of $\left(\mathrm{CH}_{3}\right)_{2} \mathrm{COO}^{+}$are shown as bar diagrams in Figures $\mathrm{S} 1$ and $\mathrm{S} 2$ of the supporting material. Predicted Franck-Condon envelopes, integrated and convolved with the resolution of the photoionization experiments, are displayed and compared to the experimental spectrum in Figure 1. FCFs were computed using both sets of B3LYP and M06-2X geometries and vibrational frequencies. The detailed patterns of the computed FCFs differ slightly with the two sets of geometries used, but the overall general patterns are very similar.

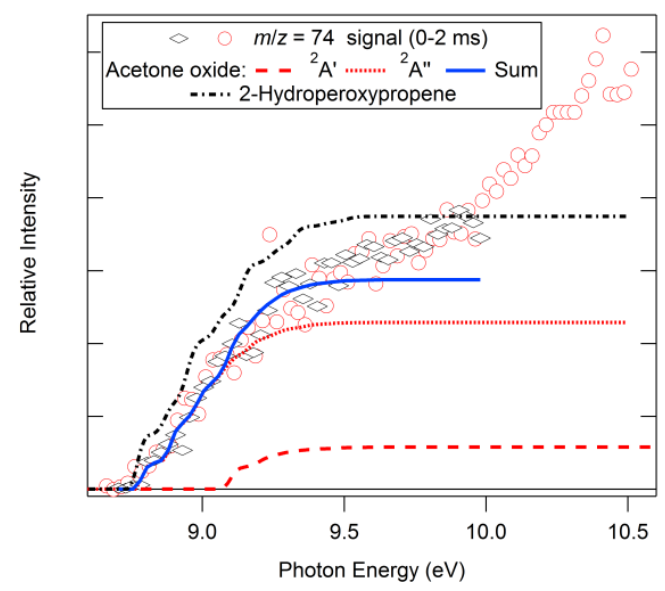

Figure 1. Photoionization spectrum of $m / z=74$ integrated over the first two milliseconds following photolysis of 2,2diiodopropane in the presence of $\mathrm{O}_{2}$ (two separate experiments are shown as the circles and the lozenges). The calculated Franck-Condon envelopes for photoionization of 2-hydroperoxypropene and of acetone oxide to its two lowest cation states are also shown. The calculated spectra of 2-hydroperoxy propene and acetone oxide are very similar. The blue line represents a best fit of the threshold region $(<9.5 \mathrm{eV})$ to a combination of Franck-Condon factors for photoionization to the two cation states of acetone oxide.

The first ionization band to the $\widetilde{\mathrm{X}}^{2} \mathrm{~A}^{\prime \prime}$ state consists of a major vibrational progression of the $14 \mathrm{a}^{\prime}$ mode (with computed harmonic frequencies of 817.3 and $834.6 \mathrm{~cm}^{-1}$ at the B3LYP/6-311++G** and M06-2X/AUG-CC-PVDZ levels respectively; Table S1). This vibrational mode is essentially a stretching mode, which delocalizes over the whole $(\mathrm{C})_{2} \mathrm{COO}$ skeleton. Based on the computed FCFs, the strongest vibrational component (i.e. the vertical ionization position) in the first ionization band of $\left(\mathrm{CH}_{3}\right)_{2} \mathrm{COO}$ is at $8.89 \mathrm{eV}$, the $\mathrm{v}^{+}=1$ vibrational component of the $14 \mathrm{a}^{\prime}$ mode. In addition, computed FCFs suggest that four to five vibrational components of this progression would have appreciable 
intensities, and this ionization band ends at $\sim 9.5 \mathrm{eV}$. For ionization to the $\widetilde{\mathrm{A}}^{2} \mathrm{~A}^{\prime}$ state, computed FCFs obtained from both sets of geometries give a very strong adiabatic vibrational component, confirming that the AIE and VIE positions of the second ionization band of $\left(\mathrm{CH}_{3}\right)_{2} \mathrm{COO}$ coincide. The next two strongest vibrational components in this band are those of the $14 \mathrm{a}^{\prime}$ (with computed frequencies, 785.8 and $817.1 \mathrm{~cm}^{-1}$; see Table S1) and $16 \mathrm{a}^{\prime}\left(373.6\right.$ and $\left.374.1 \mathrm{~cm}^{-1}\right)$ modes at 9.07 and $9.02 \mathrm{eV}$, respectively. The $14 \mathrm{a}^{\prime}$ mode is a stretching mode of the $(\mathrm{C})_{2} \mathrm{COO}$ skeleton, while the $16 \mathrm{a}^{\prime}$ mode is a $\mathrm{CCC}$ bending mode. Computed FCFs suggest that this ionization band plateaus at $\sim 9.4 \mathrm{eV}$. Based on computed AIEs and FCFs of the first two ionization bands of $\left(\mathrm{CH}_{3}\right)_{2} \mathrm{COO}$, it is concluded that these two bands will overlap, but they should be resolvable in photoelectron spectra, as their band shapes and AIE positions differ significantly.

Photoionization of other $\mathbf{C}_{3} \mathbf{H}_{6} \mathrm{O}_{2}$ isomers. The ground electronic state of $\mathrm{CH}_{2}=\mathrm{C}\left(\mathrm{CH}_{3}\right) \mathrm{OOH}$ was optimized to a $\mathrm{C}_{1}$ structure, with $\mathrm{H}$ of the $\mathrm{OH}$ group out of the $\left(\mathrm{C}_{2}\right) \mathrm{COO}$ plane, while the ground electronic state of the cation has $\mathrm{C}_{\mathrm{S}}$ symmetry $\left(\mathrm{a}^{2} \mathrm{~A}^{\prime \prime}\right.$ state) with the $\mathrm{OH}$ group in plane. In addition, the $\mathrm{CH}_{3}$ group is rotated by $\sim 60^{\circ}$ from the neutral molecule to the cation. The neutral molecule configuration with $\mathrm{C}_{\mathrm{S}}$ symmetry ( $\mathrm{OH}$ in plane) and the $\mathrm{CH}_{3}$ group with the same orientation as in the $\mathrm{C}_{1}$ minimum is a first order saddle point, with one computed imaginary frequency $\left(148 \mathrm{i} \mathrm{m}^{-1}\right)$ of the a" OH wagging mode and is only $0.19 \mathrm{kcal} \mathrm{mol}^{-1}$ higher in energy than the $\mathrm{C}_{1}$ minimum at the B3LYP/6-311++G** level of calculation, suggesting a nearly free $\mathrm{OH}$ rotation. The neutral molecule with $\mathrm{C}_{\mathrm{S}}$ symmetry $\left(\mathrm{OH}\right.$ in plane) and the $\mathrm{CH}_{3}$ group with the same orientation as in the cation is a second order saddle point (see Table S3, under neutral ${ }^{1} \mathrm{~A}^{\prime}$ ). The two vibration modes with computed imaginary frequencies (170i and $147 \mathrm{i} \mathrm{cm}^{-1}$ ) are essentially the $\mathrm{CH}_{3}$ torsional and $\mathrm{OH}$ wagging modes. This second order saddle point was computed to be $\sim 2.0 \mathrm{kcal} \mathrm{mol}^{-1}$ higher in energy than the true minimum (see Table S3), suggesting that the two imaginary modes are essentially free rotations.

The lowest cationic state of $\mathrm{CH}_{2}=\mathrm{C}\left(\mathrm{CH}_{3}\right) \mathrm{OOH}^{+}$is the $\widetilde{\mathrm{X}}^{2} \mathrm{~A}^{\prime \prime}$ state; the lowest ${ }^{2} \mathrm{~A}^{\prime}$ state is substantially higher in energy. Computed IEs to the $\widetilde{\mathrm{X}}^{2} \mathrm{~A}^{\prime \prime}$ state of $\mathrm{CH}_{2}=\mathrm{C}\left(\mathrm{CH}_{3}\right) \mathrm{OOH}^{+}$obtained at various levels of calculation are given in Table $\mathrm{S} 3$. The best theoretical estimates of the $\mathrm{AIE}_{0}$ value is $8.75 \mathrm{eV}$, only $0.04 \mathrm{eV}$ lower than the best theoretical $\mathrm{AIE}_{0}$ value for $\widetilde{\mathrm{X}}^{1} \mathrm{~A}^{\prime}$ state of $\left(\mathrm{CH}_{3}\right)_{2} \mathrm{COO}$ ionization to the $\widetilde{\mathrm{X}}^{2} \mathrm{~A}^{\prime \prime}$ state of $\left(\mathrm{CH}_{3}\right)_{2} \mathrm{COO}^{+}$. To compute FCFs for the ionization of $\mathrm{CH}_{2}=\mathrm{C}\left(\mathrm{CH}_{3}\right) \mathrm{OOH}$ the optimized geometry and computed harmonic vibrational frequencies (ignoring the two imaginary modes) of the second order saddle point of the neutral molecule (the ${ }^{1} \mathrm{~A}^{\prime}$ state discussed above) have been used instead of those of the true minimum (the $\mathrm{C}_{1} \widetilde{\mathrm{X}}^{1} \mathrm{~A}$ state), because the harmonic oscillator model cannot properly handle the $\mathrm{OH}$ wagging and $\mathrm{CH}_{3}$ torsional modes, which are essentially free rotations, as discussed above. The computed FCFs (Figure S3) suggest that the first photoelectron band of $\mathrm{CH}_{2}=\mathrm{C}\left(\mathrm{CH}_{3}\right) \mathrm{OOH}$ has a strong adiabatic vibrational component and extends to $\sim 9.6 \mathrm{eV}$.

The best computed $\mathrm{AIE}_{0}$ values of the first ionization of 3-methyl-1,2-dioxetane and dimethyldioxirane are 9.12 and $9.91 \mathrm{eV}$ (Tables S5 and S6) respectively. From the computed FCFs, the first ionization band of 3-methyl-1,2-dioxetane, which covers the 9.1 to $10.1 \mathrm{eV}$ region, has a complex vibrational structure, with major vibrational progressions in the 14a and 27a modes (essentially the methyl-ring wagging mode and bond stretches in the $\mathrm{CCOO}$ four-membered ring). The $\widetilde{\mathrm{X}}^{2} \mathrm{~A}_{2} \leftarrow \widetilde{\mathrm{X}}^{1} \mathrm{~A}_{1}$ ionization of dimethyl-dioxirane covers the 9.9 to $11.2 \mathrm{eV}$ IE region and has an even more complex vibrational structure than 3-methyl-1,2-dioxetane (Figure S5) because of significant geometry changes when ionizing from the highest doubly occupied $2 \mathrm{a}_{2}$ molecular orbital, an $\mathrm{OO} \pi$ antibonding orbital.

Quantum Chemistry. Results obtained from M06-2X/AUG-CC-PVDZ geometry optimization calculations of stationary points relevant to reactions 1 and 2 can be summarized as follows. The ground electronic state of $\left(\mathrm{CH}_{3}\right)_{2} \mathrm{CI}$ is a ${ }^{2} \mathrm{~A}^{\prime}$ state. It has a $\mathrm{C}_{\mathrm{S}}$ structure with a mirror plane through $\mathrm{CI}$ $\left(\mathrm{C}_{2} \mathrm{CI}\right.$ not planar; the two methyl groups are mirror images of each other). The lowest ${ }^{2} \mathrm{~A}$ " state has a first order saddle point with one a" imaginary vibrational frequency $\left(161 i \mathrm{~cm}^{-1}\right)$, and is slightly higher in energy than the ${ }^{2} \mathrm{~A}^{\prime}$ state (by $1.0 \mathrm{kcal} \mathrm{mol}^{-1}$ ). This saddle point has a $\mathrm{C}_{2} \mathrm{CI}$ mirror plane. For the sake 
of simplicity, only the $\widetilde{\mathrm{X}}^{2} \mathrm{~A}^{\prime}$ state is considered from here onward. The ground electronic state of $\left(\mathrm{CH}_{3}\right)_{2} \mathrm{CIOO}$ has a $\mathrm{C}_{1}$ structure. An ${ }^{2} \mathrm{~A}^{\prime \prime}$ state of $\mathrm{C}_{\mathrm{S}}$ structure (with a mirror plane through ICOO), is $0.9 \mathrm{kcal} \mathrm{mol}^{-1}$ higher in energy than the $\mathrm{C}_{1}$ lowest energy structure. Also for the sake of simplicity, only the lowest energy $\mathrm{C}_{1}$ structure is considered further.

A relaxed energy scan of the C-O bond length at the M06-2X/AUG-CC-PVDZ level shows that reaction 1 is effectively barrierless, with only a small energy barrier at $\mathrm{r}(\mathrm{CO})=2.35 \AA$, at $0.02 \mathrm{kcal}$ $\mathrm{mol}^{-1}$ with respect to a reactant complex at $\mathrm{R}(\mathrm{CO})=2.55 \AA$, and $-3.4 \mathrm{kcal} \mathrm{mol}^{-1}$ with respect to separate reactants. For reaction 2, a saddle point was located $\sim 22 \mathrm{kcal} \mathrm{mol}^{-1}$ above the $\left(\mathrm{CH}_{3}\right)_{2} \mathrm{CIOO}$ well. Computed relative energies at higher levels of calculation for both reactions 1 and 2 are summarized in Table S4. Because reaction 1 is quite exothermic, the excess energy from reaction 1 is more than sufficient to overcome the barrier of reaction 2 (the TS of reaction 2 is $\sim 9.8 \mathrm{kcal} \mathrm{mol}^{-1}$ below the reaction 1 entrance energy). The computed overall potential energy change at $0 \mathrm{~K}$ for the combined reactions 1 and 2 is $-14.4 \mathrm{kcal} \mathrm{mol}^{-1}$ (Table S4).

The calculated stationary point energies on the paths to formation of $\mathrm{CH}_{2} \mathrm{OO}$ and $\left(\mathrm{CH}_{3}\right)_{2} \mathrm{COO}$ are quite different, as shown in Figure 2. The formation of $\left(\mathrm{CH}_{3}\right)_{2} \mathrm{COO}$ is expected to be more favourable than the formation of $\mathrm{CH}_{2} \mathrm{OO}$ both kinetically and thermodynamically via the analogous sequence of reactions 1 and 2. However, $\mathrm{CH}_{2} \mathrm{OO}$ is expected to be formed vibrationally cooler than $\left(\mathrm{CH}_{3}\right)_{2} \mathrm{COO}$.

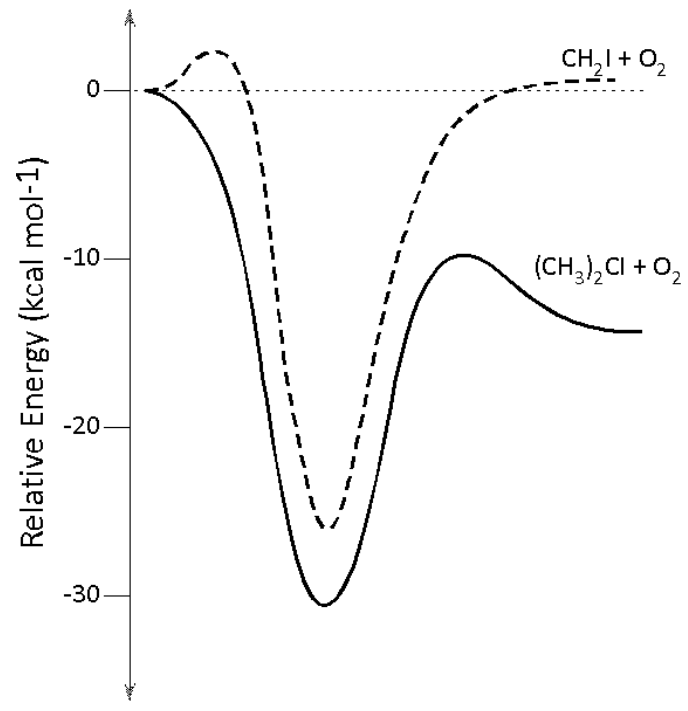

Figure 2. Calculated potential energy at $0 \mathrm{~K}$ for the stationary points in reactions of $\mathrm{CH}_{2}$ land $\left(\mathrm{CH}_{3}\right)_{2} \mathrm{Cl}$ radicals with $\mathrm{O}_{2}$ to form I atom and the corresponding Criegee intermediates, shown relative to the initial reactants at zero. Calculated values for $\mathrm{CH}_{2} \mathrm{l}+\mathrm{O}_{2}$ taken from reference ${ }^{28}$ - see supporting information for details.

\section{$\left(\mathrm{CH}_{3}\right)_{2} \mathrm{COO}$ self-reaction and unimolecular reaction}

Figure 3 shows the decay of $\left(\mathrm{CH}_{3}\right)_{2} \mathrm{COO}$ absorption following its production from the $\left(\mathrm{CH}_{3}\right)_{2} \mathrm{CI}+\mathrm{O}_{2}$ reaction in the absence of further co-reactants. Cavity ring-down spectroscopy at a wavelength of 355 $\mathrm{nm}$ was used to monitor the change in absorption by $\left(\mathrm{CH}_{3}\right)_{2} \mathrm{COO}$ over time. Significant $\left(\mathrm{CH}_{3}\right)_{2} \mathrm{CI}_{2}$ depletion signal was observed at the probe wavelength, and was isolated from overlapping absorption by the Criegee intermediate by addition of $\mathrm{CF}_{3} \mathrm{COOH}\left(>5 \times 10^{14}\right.$ molecule $\mathrm{cm}^{-3}$ ). Reactive removal of the Criegee intermediate with carboxylic acids is fast and produces products which are transparent to the probe radiation. ${ }^{17}$ The $\left(\mathrm{CH}_{3}\right)_{2} \mathrm{CI}_{2}$ photolysis depletion signal measured in this way was then subtracted from all the $\left(\mathrm{CH}_{3}\right)_{2} \mathrm{COO}$ decay traces before further analysis.

The depletion signal subtracted $\left(\mathrm{CH}_{3}\right)_{2} \mathrm{COO}$ decay traces were then fitted with first-order, secondorder and simultaneous first and second-order decay fit functions. The simultaneous first and second- 
order decay function (of course) always resulted in the best $\mathrm{R}^{2}$ value; we employ that description because of past evidence of competing unimolecular decay and rapid self reaction:

$$
\Delta \kappa(\mathrm{t})=\frac{k_{\text {pseudo }}}{\frac{k_{\text {pseudo }}}{\Delta \kappa\left(\mathrm{t}_{0}\right)} \mathrm{e}^{k_{\text {pseudo }} \mathrm{t}}-k^{\prime}\left(\frac{2 \mathrm{~L}}{\mathrm{~cd}}\right)+k^{\prime}\left(\frac{2 \mathrm{~L}}{\mathrm{~cd}}\right) \mathrm{e}^{k_{\text {pseudo }} \mathrm{t}}}
$$

Here, $\Delta \kappa$ is the difference in the ring-down rate with and without photolysis of the diiodide precursor, $L$ is the length of the cavity, $d$ is the photolysis/probe laser beam overlap length $(5.7 \mathrm{~cm}), c$ is the speed of light, $k^{\prime}$ is the second order decay rate coefficient scaled by $\sigma_{355 \mathrm{~nm}}$, the absorption cross section for the Criegee intermediate transition at $355 \mathrm{~nm}\left(k^{\prime}=k_{4} / \sigma_{355 \mathrm{~nm}}\right)$ and $k_{\text {pseudo }}$ is the first order loss rate coefficient. The decay fit functions incorporate cavity ring down measurement parameters, and a derivation of the fit function is presented in a previous publication. ${ }^{11}$

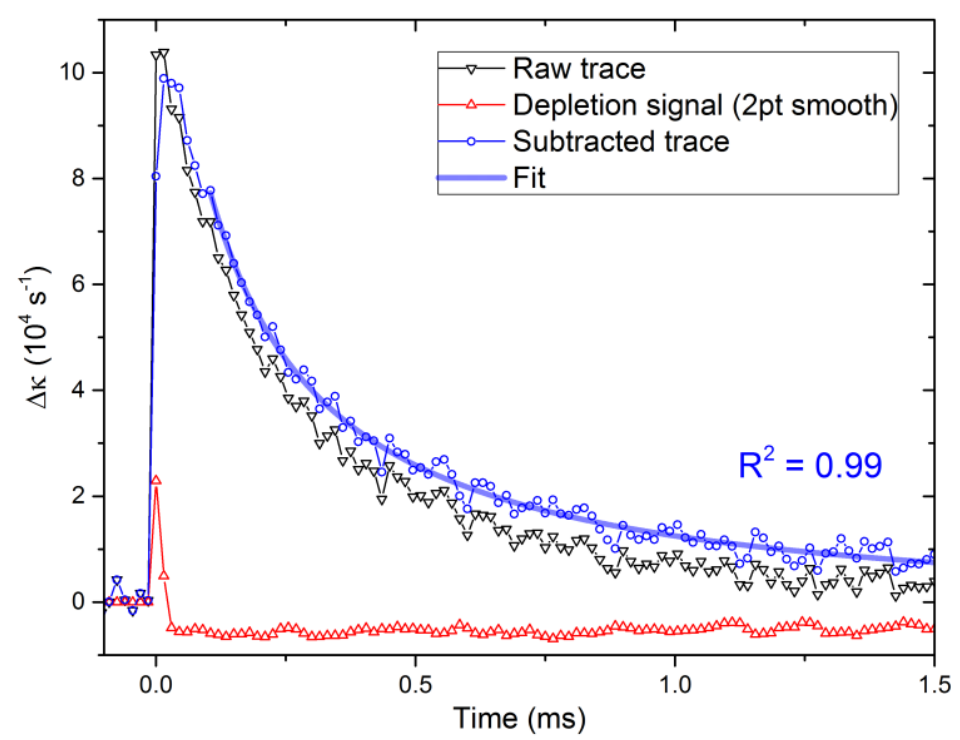

Figure 3 Example of the loss of $\left(\mathrm{CH}_{3}\right)_{2} \mathrm{COO}$ absorption at $355 \mathrm{~nm}$ because of removal of the Criegee intermediate by first and second order reactions. The open inverted triangle black trace shows the raw $\left(\mathrm{CH}_{3}\right)_{2} \mathrm{COO}$ signal decay in the absence of coreactants, and at 30 Torr total pressure. The open triangle red trace shows the depletion signal due to $\left(\mathrm{CH}_{3}\right)_{2} \mathrm{Cl}_{2}$ loss upon photolysis, details for which are given in the text. The open circle blue trace is obtained by subtraction of the depletion trace from the raw trace. The blue solid line shows a fit to a simultaneous first and second order decay function.

In the absence of added co-reagents, self-reaction and unimolecular reactions are expected to be the main loss processes for $\left(\mathrm{CH}_{3}\right)_{2} \mathrm{COO}$.

$$
\begin{gathered}
\left(\mathrm{CH}_{3}\right)_{2} \mathrm{COO}+\left(\mathrm{CH}_{3}\right)_{2} \mathrm{COO} \rightarrow \text { Products } \\
\left(\mathrm{CH}_{3}\right)_{2} \mathrm{COO} \rightarrow \text { Products }
\end{gathered}
$$

Figure 4 shows $\left(\mathrm{CH}_{3}\right)_{2} \mathrm{COO}$ decay traces obtained at various precursor concentrations. All the decay traces were obtained at 10 Torr total pressure. The dark solid lines are fits to the decay traces obtained using the simultaneous first and second order decay fit function (3). The second order decay rate coefficients obtained by freely floating $\Delta k\left(\mathrm{t}_{0}\right), k_{\text {pseudo }}$ and $k^{\prime}$ parameters in the fits are shown in the bottom inset of Figure 4. An average of these values was taken and is reported in Table 1. This averaging is based on the expectation that the second order decay rate coefficient is independent of initial $\left(\mathrm{CH}_{3}\right)_{2} \mathrm{COO}$ concentration in the regime used, ${ }^{11}$ which is supported by the data in Figure 4 . The fits were repeated by constraining $k^{\prime}$ to the averaged value and the fitted $k_{\text {pseudo }}$ values are shown in 
the top inset of Figure 4. The pseudo first order decay rate coefficients do not show any dependence on Criegee intermediate concentration, and an average was taken to provide the best estimate at 10 Torr total pressure which is reported in Table 1. Similar experiments were performed for total pressures of 30, 50 and 100 Torr using $\mathrm{N}_{2}$ as a bath gas, and the results are summarized in Table 1 and shown in Figure S7. Further details of these experiments are provided in the Supporting Information. The $k^{\prime}$ and $k_{\text {pseudo }}$ values obtained over the 10 to 100 Torr pressure range do not show a significant pressure dependence and thus were averaged to obtain pressure independent best-estimate values of $k^{\prime}$ $=(4.4 \pm 0.5) \times 10^{7} \mathrm{~cm} \mathrm{~s}^{-1}$ and $k_{\text {pseudo }}=305 \pm 70 \mathrm{~s}^{-1}$.

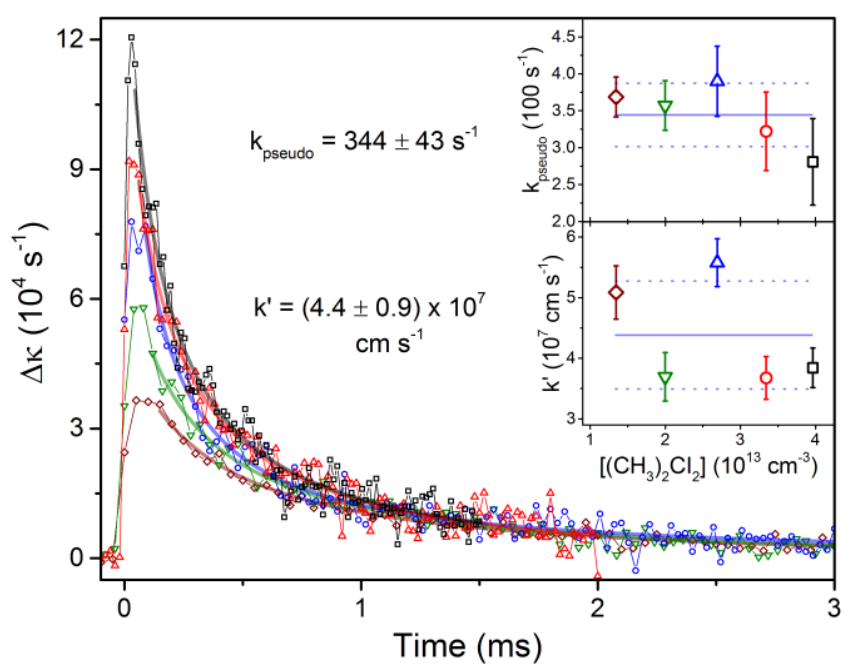

Figure 4 Pseudo-first order and second-order reaction kinetics of $\left(\mathrm{CH}_{3}\right)_{2} \mathrm{COO}$. The left plot shows $\left(\mathrm{CH}_{3}\right)_{2} \mathrm{COO}$ decay traces obtained at different concentrations of the $\left(\mathrm{CH}_{3}\right)_{2} \mathrm{CI}_{2}$ precursor. The solid lines show the fits obtained using the simultaneous first and second order decay fit function (3). The top and bottom plots in the inset show first and second order rate coefficients obtained from the fits respectively. All measurements were made at a total pressure of 10 Torr and at $293 \mathrm{~K}$.

Table 1 Summary of the fit results for self-reaction and first-order loss of $\left(\mathrm{CH}_{3}\right)_{2} \mathrm{COO}$ at different bath gas $\left(\mathrm{N}_{2}\right)$ pressures.

\begin{tabular}{|c|c|c|}
\hline Pressure (Torr) & $\left.\boldsymbol{k}^{\prime} \mathbf{( 1 0}^{\mathbf{7}} \mathbf{c m ~ s}^{\mathbf{- 1}}\right)$ & $\boldsymbol{k}_{\text {pseudo }}\left(\mathbf{s}^{\mathbf{- 1}}\right)$ \\
\hline 10 & $4.4 \pm 0.9$ & $344 \pm 43$ \\
\hline 30 & $4.7 \pm 1.3$ & $324 \pm 38$ \\
\hline 50 & $4.1 \pm 1.0$ & $276 \pm 42$ \\
\hline 100 & $4.4 \pm 0.5$ & $275 \pm 65$ \\
\hline Average & $4.4 \pm 0.5$ & $305 \pm 70$ \\
\hline
\end{tabular}

First order losses due to physical processes like diffusion and mass flow have been characterized previously and are expected to be lower than the uncertainty in the $k_{\text {pseudo }}$ value. ${ }^{11}$ The reaction of $\left(\mathrm{CH}_{3}\right)_{2} \mathrm{COO}$ with I is expected to be in the pseudo-first order limit and may contribute to the $k_{\text {pseudo }}$ value. However there is no significant systematic increase in $k_{\text {pseudo }}$ value with the increase in precursor concentration and previous studies have shown that the $\mathrm{CH}_{2} \mathrm{OO}+\mathrm{I}$ reaction rate is negligible compared to the self-reaction. ${ }^{9,11}$ Thus the $k_{\text {pseudo }}$ value obtained in this study is assigned to the unimolecular reaction rate coefficient of $\left(\mathrm{CH}_{3}\right)_{2} \mathrm{COO}$. This value is in good agreement with the calculated unimolecular reaction rate coefficient value, $369 \mathrm{~s}^{-1}$ at $298 \mathrm{~K}$, obtained using master equation calculations and RRKM theory by Lester and co-workers. ${ }^{31}$ Newland et al. ${ }^{13}$ reported a $\left(\mathrm{CH}_{3}\right)_{2} \mathrm{COO}$ unimolecular reaction rate coefficient value of $151 \pm 35 \mathrm{~s}^{-1}$, which was obtained from a 
study of the ozonolysis of 2,3-dimethyl-but-2-ene, and is in reasonable agreement with the value from the current study. All of these values are an order of magnitude larger than the unimolecular decay rate coefficient value, $11.6 \pm 8.0 \mathrm{~s}^{-1}$, that we previously reported for $\mathrm{CH}_{2} \mathrm{OO}$. ${ }^{11}$ These observations are broadly consistent with unimolecular reaction rate coefficient values predicted by Olzmann and coworkers. ${ }^{32} \mathrm{UV}$ depletion studies coupled with photoionization mass spectrometry ${ }^{29}$ have shown relative yields of $\mathrm{OH}$ radical to be greater from $\left(\mathrm{CH}_{3}\right)_{2} \mathrm{COO}$ than from $\mathrm{CH}_{2} \mathrm{OO}$. These observations suggest that facile intramolecular hydrogen transfer leads to a greater unimolecular reaction rate coefficient in $\left(\mathrm{CH}_{3}\right)_{2} \mathrm{COO}$ compared to $\mathrm{CH}_{2} \mathrm{OO}$.

Table 2: Comparison of the observed and calculated self-reaction and unimolecular rate coefficient values for $\mathrm{CH}_{2} \mathrm{OO}$ and $\left(\mathrm{CH}_{3}\right)_{2} \mathrm{COO}$ Criegee intermediates.

\begin{tabular}{|c|c|c|c|c|c|}
\hline \multirow{2}{*}{$\begin{array}{c}\text { Criegee } \\
\text { intermediate }\end{array}$} & \multicolumn{3}{|c|}{$\begin{array}{l}\text { Self-reaction rate coefficient, } k_{4}, \\
\qquad\left(10^{-11} \mathrm{~cm}^{3} \mathrm{~s}^{-1}\right)\end{array}$} & \multicolumn{2}{|c|}{$\begin{array}{c}\text { Unimolecular loss rate, } k_{5}, \\
\left(\mathrm{~s}^{-1}\right)\end{array}$} \\
\hline & CRDS & Collision limit & Capture limit & CRDS & Theory \\
\hline $\mathrm{CH}_{2} \mathrm{OO}$ & $7.4 \pm 0.6^{11}$ & 12 & 208 & $11.6 \pm 8.0^{11}$ & $0.33^{32}$ \\
\hline$\left(\mathrm{CH}_{3}\right)_{2} \mathrm{COO}$ & $\begin{array}{c}60 \pm 11 \\
\text { (this work) }\end{array}$ & 17 & 198 & $\begin{array}{c}305 \pm 70 \\
\text { (this work) }\end{array}$ & $250,{ }^{32} 369^{31}$ \\
\hline
\end{tabular}

Self-reaction of the simplest Criegee intermediate, $\mathrm{CH}_{2} \mathrm{OO}$, has been found to be fast ${ }^{9-11}$ and the $\left(\mathrm{CH}_{3}\right)_{2} \mathrm{COO}$ self-reaction is also expected to be rapid. Thus, the second order component of the decay is assigned to the self-reaction of $\left(\mathrm{CH}_{3}\right)_{2} \mathrm{COO}$. Similar to the self-reaction of $\mathrm{CH}_{2} \mathrm{OO}$, which has been shown to be independent of pressure both experimentally ${ }^{9}$ and computationally, ${ }^{10}$ the second order decay rate coefficient for $\left(\mathrm{CH}_{3}\right)_{2} \mathrm{COO}$ loss does not show significant pressure dependence within the 10 to 100 Torr range. The pressure independent $k^{\prime}$ value can be converted into an absolute selfreaction rate coefficient using a value for the absorption cross section for the $\left(\mathrm{CH}_{3}\right)_{2} \mathrm{COO} \widetilde{\mathrm{B}}{ }^{1} \mathrm{~A}^{\prime} \leftarrow$ $\widetilde{\mathrm{X}}{ }^{1} \mathrm{~A}^{\prime}$ transition at the probe wavelength $355 \mathrm{~nm}$. We determine a value for this absorption cross section by analysing the photolysis laser induced depletion of $\left(\mathrm{CH}_{3}\right)_{2} \mathrm{CI}_{2}$ signals evident in Figure 5. Figure 5 shows precursor diiodide depletion measurements made by adding trifluoracetic acid to our gas mixture to remove promptly any subsequently formed $\left(\mathrm{CH}_{3}\right)_{2} \mathrm{COO}$.

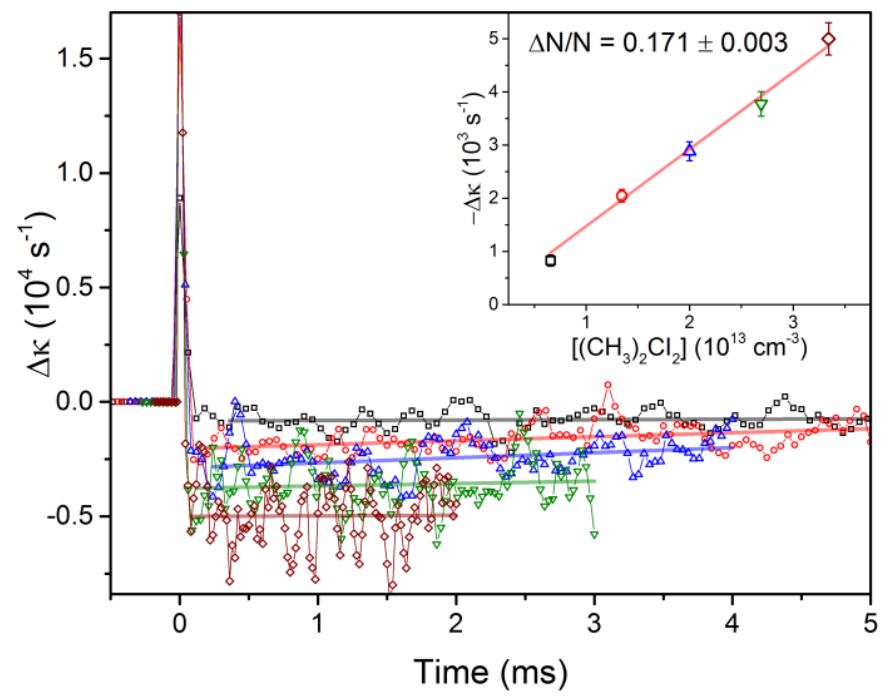

Figure 5 Depletion of $\left(\mathrm{CH}_{3}\right) \mathrm{Cl}_{2}$ signal at different $\left(\mathrm{CH}_{3}\right)_{2} \mathrm{Cl}_{2}$ concentrations. The left plots show the depletion of $\left(\mathrm{CH}_{3}\right)_{2} \mathrm{Cl}_{2}$ signal at various $\left(\mathrm{CH}_{3}\right)_{2} \mathrm{Cl}_{2}$ concentrations for the same photolysis laser power. These depletion traces were used to correct the kinetic traces for Criegee intermediate reactions in Figure 4, as illustrated in Figure 3. The solid lines are linear fits to the 
depletion traces and the intercept values at zero time were taken as best estimates for the depletion signals. The inset shows a plot of the intercept values as a function of $\left(\mathrm{CH}_{3}\right)_{2} \mathrm{Cl}_{2}$ concentration. The solid line is a linear fit whose slope is related to the fractional depletion of $\left(\mathrm{CH}_{3}\right)_{2} \mathrm{Cl}_{2}$.

The depletion signal can be related to the fractional loss of $\left(\mathrm{CH}_{3}\right)_{2} \mathrm{CI}_{2}$ molecules, $\Delta \mathrm{N} / \mathrm{N}^{0}$, using

$$
\Delta \kappa=\left(\frac{\mathrm{dc} \sigma_{355 \mathrm{~nm}}}{\mathrm{~L}}\right)\left(\frac{\Delta \mathrm{N}}{\mathrm{N}^{0}}\right) \mathrm{N}^{0}
$$

Here $\mathrm{N}^{0}$ denotes the initial number density of the diiodide and all other symbols represent the same parameters as used in equation 3 . The $\sigma_{355 n m}$ value for $\left(\mathrm{CH}_{3}\right)_{2} \mathrm{CI}_{2}$ was determined by comparing to reference measurements for $\mathrm{CH}_{2} \mathrm{I}_{2}$ (Figure S6), details of which are provided in the Supporting Information. If we assume an overall yield of unity for formation of $\left(\mathrm{CH}_{3}\right)_{2} \mathrm{COO}$ via reactions 1 and 2, the fractional loss of $\left(\mathrm{CH}_{3}\right)_{2} \mathrm{CI}_{2}$ following photo-dissociation can be converted to the $\left(\mathrm{CH}_{3}\right)_{2} \mathrm{COO}$ concentration. The yield for formation of $\mathrm{CH}_{2} \mathrm{OO}$ from $\mathrm{CH}_{2} \mathrm{I}_{2}$ is close to unity $(0.79)$ at the 10 Torr pressure used here. ${ }^{33-35}$ Formation of $\left(\mathrm{CH}_{3}\right)_{2} \mathrm{COO}$ is expected to be both kinetically and thermodynamically more favourable than the formation of $\mathrm{CH}_{2} \mathrm{OO}$, via the corresponding sequence of reactions 1 and 2, hence a yield of 0.79 to 1 should be a good approximation. Using equation 6 , with the $\Delta \kappa\left(\mathrm{t}_{0}\right)$ values obtained from the data analysis and the initial $\left(\mathrm{CH}_{3}\right)_{2} \mathrm{COO}$ concentration values, $\Delta \mathrm{N}$, obtained from the measured fractional losses of $\left(\mathrm{CH}_{3}\right)_{2} \mathrm{CI}_{2}$ and yield of 0.79 to 1 , a value of $\sigma_{355 \mathrm{~nm}}=$ $(1.45 \pm 0.24) \times 10^{-17} \mathrm{~cm}^{2}$ was obtained for the $\left(\mathrm{CH}_{3}\right)_{2} \mathrm{COO}$ Criegee intermediate. This value is in agreement with $\sigma_{356 \mathrm{~nm}}=\left(1.1_{-0.6}^{+1.1}\right) \times 10^{-17} \mathrm{~cm}^{2}$ reported previously using photo-depletion methods coupled with mass spectrometry. ${ }^{22}$ A self-reaction rate coefficient $k_{4}=(6.0 \pm 1.1) \times 10^{-10} \mathrm{~cm}^{3} \mathrm{~s}^{-1}$ is therefore obtained from the $k^{\prime}$ and $\sigma_{355 \mathrm{~nm}}$ values obtained from the current work.

Table 2 compares self-reaction rate coefficient values for $\left(\mathrm{CH}_{3}\right)_{2} \mathrm{COO}$ and $\mathrm{CH}_{2} \mathrm{OO}$; although both are fast, the former is significantly larger. The two rate coefficients are also compared with limiting rate coefficients estimated from the collision frequency and a dipole-dipole capture model. The collisionlimited reaction rate coefficient for the self-reaction of either Criegee intermediate was estimated using:

$$
k=\pi\left(d_{\text {Criegee }}\right)^{2}\left(\frac{8 k_{B} T}{\pi \frac{m_{\text {Criegee }}}{2}}\right)^{1 / 2}
$$

where $d_{\text {Criegee }}$ is the molecular diameter of the Criegee intermediate, $k_{B}$ is the Boltzmann constant, $m_{\text {Criegee }}$ is the mass of the Criegee intermediate and $T$ is the absolute temperature. Figure 6 shows the optimized ground state geometries of $\mathrm{CH}_{2} \mathrm{OO}$ and $\left(\mathrm{CH}_{3}\right)_{2} \mathrm{COO}$ calculated at the B3LYP/6$31+\mathrm{G}(\mathrm{d})$ level of theory. The distance between the terminal oxygen and the most distant hydrogen atom was taken as the best estimate for the maximum molecular diameter. The experimental value for the self-reaction of $\mathrm{CH}_{2} \mathrm{OO}$ is lower than the collision limited value, whereas for $\left(\mathrm{CH}_{3}\right)_{2} \mathrm{COO}$ the reverse is true. 
a)

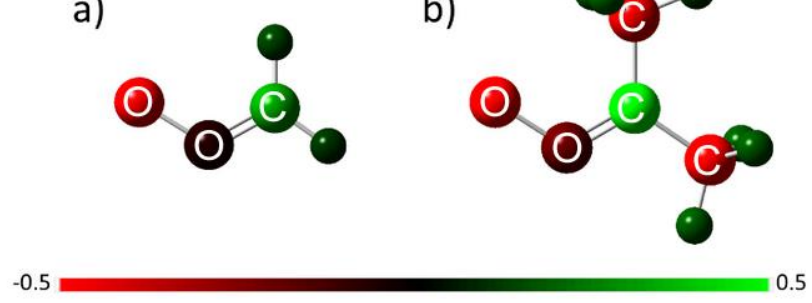

Figure 6: Ground-state optimized geometries of a) $\mathrm{CH}_{2} \mathrm{OO}$ and b) $\left(\mathrm{CH}_{3}\right)_{2} \mathrm{COO}$. The red to green colour gradients show the electrostatic potential (ESP) fitted partial atomic charges. All calculations were performed at the CCSD(T)/aug-cc$p V T Z / / B 3 L Y P / 6-31+G(d)$ level of theory.

Table 2 also shows the capture-limited rate coefficient values for the self-reactions of $\mathrm{CH}_{2} \mathrm{OO}$ and $\left(\mathrm{CH}_{3}\right)_{2} \mathrm{COO}$, obtained using calculated dipole moments. Long-range interactions such as those between two permanent dipole moments will promote capture of reacting molecules at separations greater than their physical dimensions, and will determine the limiting rate coefficient in the absence of steric restrictions and potential energy barriers along the reaction pathway. Figure 6 shows the calculated partial atomic charges at the $\mathrm{CCSD}(\mathrm{T}) /$ aug-cc-pVTZ level of theory for the B3LYP optimized geometries of $\mathrm{CH}_{2} \mathrm{OO}$ and $\left(\mathrm{CH}_{3}\right)_{2} \mathrm{COO}$. These Criegee intermediates were calculated to have relatively large dipole moments of $5.81 \mathrm{D}$ for $\mathrm{CH}_{2} \mathrm{OO}$ and $6.67 \mathrm{D}$ for $\left(\mathrm{CH}_{3}\right)_{2} \mathrm{COO}$. Under these circumstances, reaction cross sections can exceed the collision cross section values. If the dipoledipole interaction is the dominant attractive interaction between molecules, a capture cross section is derived as:

$$
\sigma=3 \pi\left(\frac{\mu_{1} \mu_{2}}{3\left(4 \pi \varepsilon_{0}\right) k_{b} T}\right)^{2 / 3}
$$

where $\mu_{1}$ and $\mu_{2}$ are the dipole moments of the two reacting molecules and $\varepsilon_{0}$ is the permittivity of free space. ${ }^{36}$ The dipole capture limited reaction rate coefficient for the self-reaction of Criegee intermediates is then given by

$$
k=\left(\frac{18}{\pi k_{b} T \varepsilon_{0}^{4}}\right)^{1 / 6} \frac{\left(\mu_{\text {Criegee }}\right)^{4 / 3}}{\left(m_{\text {Criegee }} / 2\right)^{1 / 2}}
$$

where $\mu_{\text {Criegee }}$ and $m_{\text {Criegee }}$ are the dipole moment and the mass of the Criegee intermediate, respectively. ${ }^{36}$ Larger dipole moments give stronger long-range attractions and consequently a larger dipole capture limited self-reaction rate coefficient value for $\left(\mathrm{CH}_{3}\right)_{2} \mathrm{COO}$ compared to $\mathrm{CH}_{2} \mathrm{OO}$. Although the self-reaction rate coefficient value for $\left(\mathrm{CH}_{3}\right)_{2} \mathrm{COO}$ might be larger than the collision limited value, it is lower than the capture limited value of $19.8 \times 10^{-10} \mathrm{~cm}^{3} \mathrm{~s}^{-1}$, reflecting further geometrical constraints on the reaction rate.

Previous computational studies have shown that the self-reaction of $\mathrm{CH}_{2} \mathrm{OO}$ is exothermic and forms formaldehyde and singlet oxygen, $\mathrm{O}_{2}\left({ }^{1} \Delta_{\mathrm{g}}\right) .{ }^{10}$ Computed energy changes for these two reactions are shown in Table 3.The corresponding self-reaction of $\left(\mathrm{CH}_{3}\right)_{2} \mathrm{COO}$ will be similarly exothermic and produces acetone and $\mathrm{O}_{2}\left({ }^{1} \Delta_{\mathrm{g}}\right)$. The reaction pathways are expected to be barrierless (or nearly so), with reaction rates controlled by strongly attractive intermolecular interactions, consistent with the observed rate coefficient trend. 
Table 3: Energetics for the self-reactions of $\mathrm{CH}_{2} \mathrm{OO}$ and $\left(\mathrm{CH}_{3}\right)_{2} \mathrm{COO}$ calculated at the CBS-QB3 and rG4 levels of theory.

\begin{tabular}{|l|l|l|}
\hline \multirow{2}{*}{ Reaction } & \multicolumn{2}{|l|}{$\Delta \mathbf{E}$ at 0 K $\left(\mathbf{k c a l ~ m o l}^{-1}\right)$} \\
\cline { 2 - 3 } & $\mathbf{C B S}-\mathbf{Q B 3}$ & $\mathbf{G 4}$ \\
\hline$\left(\mathrm{CH}_{3}\right)_{2} \mathrm{COO}+\left(\mathrm{CH}_{3}\right)_{2} \mathrm{COO} \rightarrow 2\left(\mathrm{CH}_{3}\right)_{2} \mathrm{CO}+\mathrm{O}_{2}\left({ }^{1} \Delta_{g}\right)$ & -68.4 & -69.3 \\
\hline $\mathrm{H}_{2} \mathrm{COO}+\mathrm{H}_{2} \mathrm{COO} \rightarrow 2 \mathrm{H}_{2} \mathrm{CO}+\mathrm{O}_{2}\left({ }^{1} \Delta_{g}\right)$ & -76.0 & -76.0 \\
\hline
\end{tabular}

Self-reaction of $\left(\mathrm{CH}_{3}\right)_{2} \mathrm{COO}$ is not expected to be significant in the atmosphere as the concentration of the Criegee intermediates will be low. However, this reaction will be important in laboratory studies where high concentrations of $\left(\mathrm{CH}_{3}\right)_{2} \mathrm{COO}$ may be generated, and thus needs to be characterized to obtain accurate bimolecular reaction rate coefficients from fitting of kinetic data. Unimolecular reaction of $\left(\mathrm{CH}_{3}\right)_{2} \mathrm{COO}$ will be important under both laboratory and atmospheric conditions. For collisionally stabilized $\mathrm{CH}_{2} \mathrm{OO}$ and $\mathrm{CH}_{3} \mathrm{CHOO}$, reaction with water dimer and water respectively dominate their loss processes in the atmosphere. However, the corresponding reactions of $\left(\mathrm{CH}_{3}\right)_{2} \mathrm{COO}$ with water and water dimer are relatively slow. ${ }^{12,15,37}$ Thus, the unimolecular reaction is expected to be a significant sink for $\left(\mathrm{CH}_{3}\right)_{2} \mathrm{COO}$ in the troposphere.

\section{$\left(\mathrm{CH}_{3}\right)_{2} \mathrm{COO}+\mathrm{SO}_{2}$ reaction}

The reaction of acetone oxide with $\mathrm{SO}_{2}$,

$$
\left(\mathrm{CH}_{3}\right)_{2} \mathrm{COO}+\mathrm{SO}_{2} \rightarrow \text { Products }
$$

has been investigated in the present work by both cavity ring down and photoionization methods.

Cavity ring down measurements. Figure 7 shows the cavity ring-down decay traces of $\left(\mathrm{CH}_{3}\right)_{2} \mathrm{COO}$ in the presence of different concentrations of $\mathrm{SO}_{2}$. These traces were fitted with the same simultaneous first and second order decay fit function (3) as used for the background $\left(\mathrm{CH}_{3}\right)_{2} \mathrm{COO}$ loss. The second order rate coefficient was fixed to the pressure independent $k^{\prime}$ value obtained from the background loss fitting described previously, whereas the $k_{\text {pseudo }}$ value was floated in the fits. The first order contribution results from the pseudo first order reaction of $\left(\mathrm{CH}_{3}\right)_{2} \mathrm{COO}$ with $\mathrm{SO}_{2}$, which is in excess. The first order rate coefficient values obtained from the fits were then plotted as a function of $\mathrm{SO}_{2}$ concentration, and a linear fit gives the bimolecular rate coefficient for the $\left(\mathrm{CH}_{3}\right)_{2} \mathrm{COO}+\mathrm{SO}_{2}$ reaction. The unimolecular loss of $\left(\mathrm{CH}_{3}\right)_{2} \mathrm{COO}$ does not contribute to the gradient of the linear fit, but dominates the intercept value. Figure 8 shows the rate coefficient values measured at various bath gas $\left(\mathrm{N}_{2}\right)$ pressures. There is a weak bath gas pressure dependence within the 10 to 40 Torr range (Table 5). The values obtained between the 50 and 100 Torr range are within the bounds of uncertainties and were averaged to obtained the best estimate for the high pressure limit $k_{9}=(2.2 \pm 0.1) \times 10^{-10} \mathrm{~cm}^{3} \mathrm{~s}^{-1}$. 


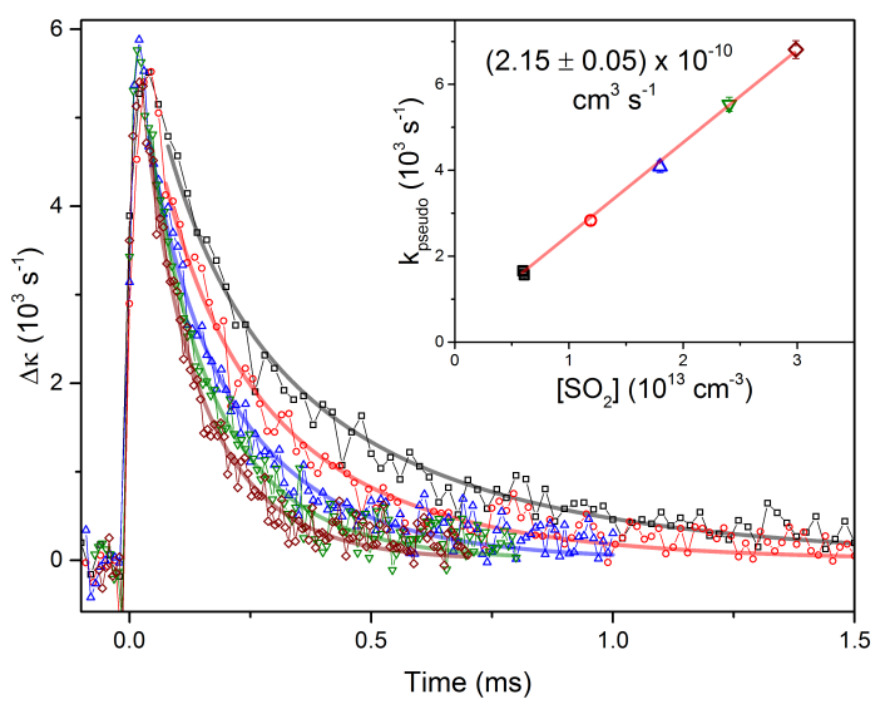

Figure 7: $\left(\mathrm{CH}_{3}\right)_{2} \mathrm{COO}$ decay traces obtained at different $\mathrm{SO}_{2}$ concentrations. The solid lines show the fits using the simultaneous first and second order decay fit function (3). All the decay traces were taken at 50 Torr total pressure $\left(N_{2}\right)$. The inset shows the linear fit to the pseudo first order rate coefficients obtained from the decay fits.

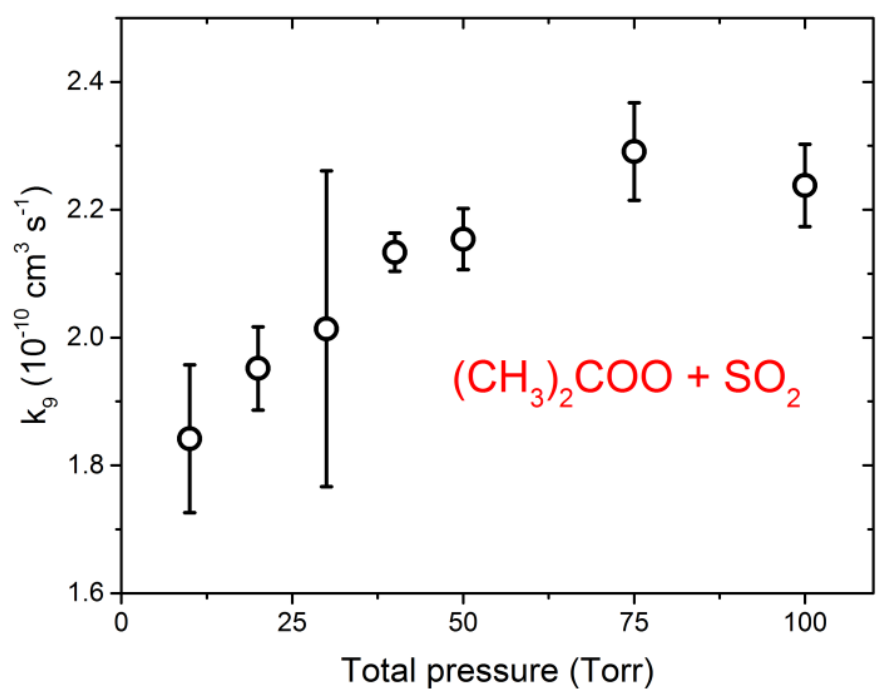

Figure 8: $\left(\mathrm{CH}_{3}\right)_{2} \mathrm{COO}+\mathrm{SO}_{2}$ reaction rate coefficient as a function of bath gas $\left(\mathrm{N}_{2}\right)$ pressure.

Table 5. $\left(\mathrm{CH}_{3}\right)_{2} \mathrm{COO}+\mathrm{SO}_{2}$ reaction rate coefficients measured by cavity ring down spectroscopy

\begin{tabular}{|c|c|}
\hline Total pressure (Torr $\left.\mathbf{N}_{\mathbf{2}}\right)$ & $\mathbf{k}_{\mathbf{9}} \mathbf{( 1 0}^{-\mathbf{1 0}} \mathbf{c m}^{-\mathbf{3}} \mathbf{)}$ \\
\hline 10 & $1.84 \pm 0.12$ \\
\hline 20 & $1.95 \pm 0.07$ \\
\hline 30 & $2.01 \pm 0.25$ \\
\hline 40 & $2.13 \pm 0.03$ \\
\hline 50 & $2.15 \pm 0.05$ \\
\hline 75 & $2.29 \pm 0.08$ \\
\hline 100 & $2.24 \pm 0.06$ \\
\hline
\end{tabular}

Photoionization mass spectrometry. The observed decay of the $\mathrm{m} / z=74$ signal becomes more rapid as the concentration of $\mathrm{SO}_{2}$ is increased. In the photoionization experiments wall losses increase the 
zero-reagent first-order removal of acetone oxide, and the lower concentration of the Criegee intermediate reduces the self-reaction relative to the cavity ring down measurements, so a pseudo-first order analysis is suitable. The pseudo-first order decays are rapid enough that the measured instrument response must be included to correctly analyze the time constants, as described in earlier publications. ${ }^{7-8}$ A linear fit to the dependence of the pseudo-first order rate constant on $\left[\mathrm{SO}_{2}\right]$, as shown in Figure 9, returns the second order bimolecular rate coefficient as the slope. Huang et al. ${ }^{12}$ report a decrease in the rate coefficient for this reaction with decreasing pressure below about 100 Torr $\left(\mathrm{N}_{2} / \mathrm{O}_{2}\right.$ buffer $)$, but the present measurement at 4 Torr $\mathrm{He},(7.3 \pm 0.5) \times 10^{-11} \mathrm{~cm}^{3} \mathrm{~s}^{-1}$, is similar to Huang et al.'s measurement at 20 Torr, $(7.0 \pm 0.4) \times 10^{-11} \mathrm{~cm}^{3} \mathrm{~s}^{-1} .{ }^{12}$ Photoionization measurements at 10 Torr (Figure S8) appear to yield a larger rate coefficient, $(1.5 \pm 0.5) \times 10^{-10} \mathrm{~cm}^{3} \mathrm{~s}^{-1}$. This value agrees within mutual uncertainties with the value of $(1.84 \pm 0.12) \times 10^{-10} \mathrm{~cm}^{3} \mathrm{~s}^{-1}$ obtained at 10 Torr $\mathrm{N}_{2}$ determined in the cavity ring down measurements. As this reaction shows pressure dependence, ${ }^{12} \mathrm{a}$ difference in energy transfer efficiency between $\mathrm{He}$ and $\mathrm{N}_{2}$, may be the reason that the two present determinations at 10 Torr differ slightly. However, the present rate coefficients measured by both cavity ring down and photoionization methods are larger than measurements at similar conditions reported by Huang et al. ${ }^{12}$ Measurements at 4 Torr of the reaction of deuterated acetone oxide, $\left(\mathrm{CD}_{3}\right)_{2} \mathrm{COO}$, with $\mathrm{SO}_{2}$ show an inverse kinetic isotope effect (Figure $\mathrm{S} 9$ ), with the deuterated rate coefficient, $(1.37 \pm 0.12) \times 10^{-10} \mathrm{~cm}^{3} \mathrm{~s}^{-1}$, approximately twice the rate coefficient for the undeuterated reaction. This inverse kinetic isotope effect, $k_{\mathrm{H}} / k_{\mathrm{D}}=0.53 \pm 0.06$, could reflect more effective collisional stabilization of the deuterated association complex because of the increased density of vibrational states. At 10 Torr total pressure, measurements were also taken at high photon energies $(13 \mathrm{eV})$ to follow the formation of $\mathrm{SO}_{3}$ product. The rise time of the $\mathrm{SO}_{3}$ agrees reasonably well with the observed decay of $\left(\mathrm{CH}_{3}\right)_{2} \mathrm{COO}$ (Figure $\mathrm{S} 10$ ), confirming that $\mathrm{SO}_{3}$ is a direct product of the reaction of $\left(\mathrm{CH}_{3}\right)_{2} \mathrm{COO}$ with $\mathrm{SO}_{2}$.

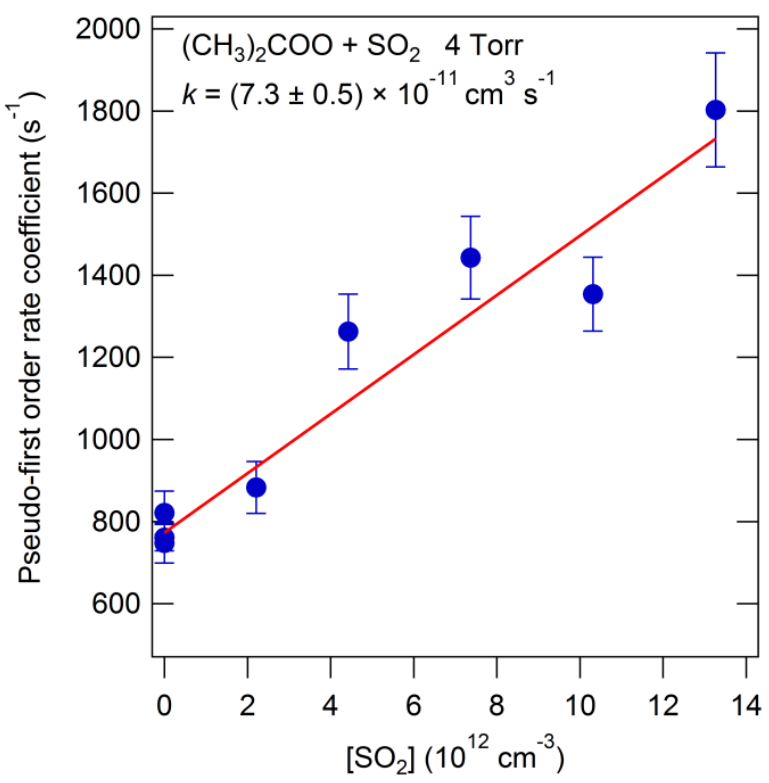

Figure 9. Representative plot of pseudo-first order decay coefficients for acetone oxide as a function of [SO $\left.\mathrm{S}_{2}\right]$, measured by photoionization mass spectrometry

Table compares previously reported rate coefficient values for different Criegee intermediate reactions with $\mathrm{SO}_{2}$ with those measured in this work. The syn- conformer of $\mathrm{CH}_{3} \mathrm{CHOO}$ and the simplest Criegee intermediate $\mathrm{CH}_{2} \mathrm{OO}$ react with $\mathrm{SO}_{2}$ at similar rates. However, the anti- conformer of $\mathrm{CH}_{3} \mathrm{CHOO}$ reacts significantly faster with $\mathrm{SO}_{2}$. Its rate coefficient, reported by Sheps et al. ${ }^{20}$ is similar to the rate coefficient for the $\left(\mathrm{CH}_{3}\right)_{2} \mathrm{COO}+\mathrm{SO}_{2}$ reaction measured in this work. Both of these rate coefficients are similar to or larger than the calculated collision limit $\left(\sim 1.5 \times 10^{-10} \mathrm{~cm}^{3} \mathrm{~s}^{-1}\right)$ at 293 K. Thus, long range attractive interactions should play a significant role. These Criegee intermediates 
have somewhat greater dipole moments $\left(6.86 \mathrm{D}\right.$ for anti- $\mathrm{CH}_{3} \mathrm{CHOO}$ and $6.67 \mathrm{D}$ for $\left.\left(\mathrm{CH}_{3}\right)_{2} \mathrm{COO}\right)$ than do the more slowly reacting Criegee intermediates (5.81 D for $\mathrm{CH}_{2} \mathrm{OO}$ and $5.98 \mathrm{D}$ for syn-

$\mathrm{CH}_{3} \mathrm{CHOO}$ ).

Table 6: Comparison of measured rate coefficients of reactions of different Criegee intermediates with $\mathrm{SO}_{2}$.

\begin{tabular}{|l|l|}
\hline $\begin{array}{l}\text { Criegee } \\
\text { Intermediate }\end{array}$ & Rate coefficient $\left(\mathbf{1 0}^{-\mathbf{1 1}} \mathbf{c m}^{\mathbf{3}} \mathbf{s}^{-\mathbf{1}}\right)$ \\
\hline $\mathrm{CH}_{2} \mathrm{OO}$ & $3.9 \pm 0.7,{ }^{7} 3.80 \pm 0.04^{11}$ \\
\hline syn- $\mathrm{CH}_{3} \mathrm{CHOO}$ & $2.4 \pm 0.3,{ }^{8} 2.9 \pm 0.3^{20}$ \\
\hline anti-CH${ }_{3} \mathrm{CHOO}$ & $6.7 \pm 1.0,{ }^{8} 22 \pm 2^{20}$ \\
\hline & $13.2 \pm 1.3$ (high-pressure limit) \\
& $22 \pm 1$ (high-pressure limit CRD) \\
$\left(\mathrm{CH}_{3}\right)_{2} \mathrm{COO}$ & $15 \pm 5(10$ Torr PIMS) \\
& $7.3 \pm 0.5$ (4 Torr PIMS) \\
\hline$\left(\mathrm{CD}_{3}\right)_{2} \mathrm{COO}$ & $13.7 \pm 1.2$ (4 Torr PIMS) \\
\hline
\end{tabular}

$\left(\mathrm{CD}_{3}\right)_{2} \mathrm{COO}+\mathrm{NO}_{2}$

The reactions of Criegee intermediates with $\mathrm{NO}_{2}$ are substantially slower than reactions with $\mathrm{SO}_{2}$, but oxidation of $\mathrm{NO}_{2}$ by carbonyl oxides may play a role in nitrate formation in urban and indoor atmospheres. Because of the ultraviolet absorption of $\mathrm{NO}_{2}$, measurement of rate coefficients in the cavity ring down apparatus is problematic, so measurements were carried out by photoionization. The photolysis wavelength is chosen to be $248 \mathrm{~nm}$, where $\mathrm{NO}_{2}$ absorbs less strongly than at $351 \mathrm{~nm}$. A long-time background at the mass of acetone oxide (see below) prevented reliable measurement of a rate coefficient for the reaction of $\left(\mathrm{CH}_{3}\right)_{2} \mathrm{COO}$ with $\mathrm{NO}_{2}$. A fit of the slope of a plot of pseudo-first order rate coefficients vs. $\mathrm{NO}_{2}$ concentration gave a $95 \%$ uncertainty bound larger than the value. This result, $(2.3 \pm 2.5) \times 10^{-12} \mathrm{~cm}^{3} \mathrm{~s}^{-1}$ should therefore be interpreted as an upper bound on the rate coefficient of $k\left(\left(\mathrm{CH}_{3}\right)_{2} \mathrm{COO}+\mathrm{NO}_{2}\right) \leq 5 \times 10^{-12} \mathrm{~cm}^{3} \mathrm{~s}^{-1}$. However, in the case of deuterated acetone oxide the background had a negligible effect and the rate coefficient for $\left(\mathrm{CD}_{3}\right)_{2} \mathrm{COO}$ with $\mathrm{NO}_{2}$ (see Figure S11) is measured as $(2.1 \pm 0.3) \times 10^{-12} \mathrm{~cm}^{3} \mathrm{~s}^{-1}$. This value is very similar to rate constants measured for $\mathrm{CH}_{3} \mathrm{CHOO}$ with $\mathrm{NO}_{2}$, for which Taatjes et al. ${ }^{8}$ reported $(2 \pm 1) \times 10^{-12} \mathrm{~cm}^{3} \mathrm{~s}^{-1}$ as a value for both conformers. The initial report of $\mathrm{CH}_{2} \mathrm{OO}$ reaction with $\mathrm{NO}_{2}$ from Welz et al., ${ }^{7} 7_{-2}^{+3} \times 10^{-12}$ $\mathrm{cm}^{3} \mathrm{~s}^{-1}$, is substantially larger than subsequent measurements, for example by Stone et al. ${ }^{14}$ who measured a pressure-independent rate coefficient of $(1.5 \pm 0.5) \times 10^{-12} \mathrm{~cm}^{3} \mathrm{~s}^{-1}$. The overall body of data appears to show that all carbonyl oxides react with $\mathrm{NO}_{2}$ with similar rate coefficients.

The reactions of carbonyl oxides with $\mathrm{NO}_{2}$ are thought to eventually result in nitrate radical formation, ${ }^{19,38}$ but attempts to measure $\mathrm{NO}_{3}$ products from the reaction of $\left(\mathrm{CD}_{3}\right)_{2} \mathrm{COO}$ with $\mathrm{NO}_{2}$ failed, as have similar attempts for other carbonyl oxide reactions with $\mathrm{NO}_{2} \cdot{ }^{7-8}$ Also, as in measurements of other Criegee intermediate reactions with $\mathrm{NO}_{2}$, the yield of the presumed carbonyl co-product of $\mathrm{NO}_{3}$, acetone in this case, decreases with increasing $\mathrm{NO}_{2}$ concentration. Perhaps formation of an association complex occurs under the present conditions, and eventual nitrate production observed in ozonolysis experiments may result from further reaction of this complex. Although a weak parent ion signal for the association product was observed in the reaction of $\mathrm{CH}_{3} \mathrm{CHOO}$ with $\mathrm{NO}_{2}{ }^{8}$ no signal was observed at the mass of the association product in the present experiments. 


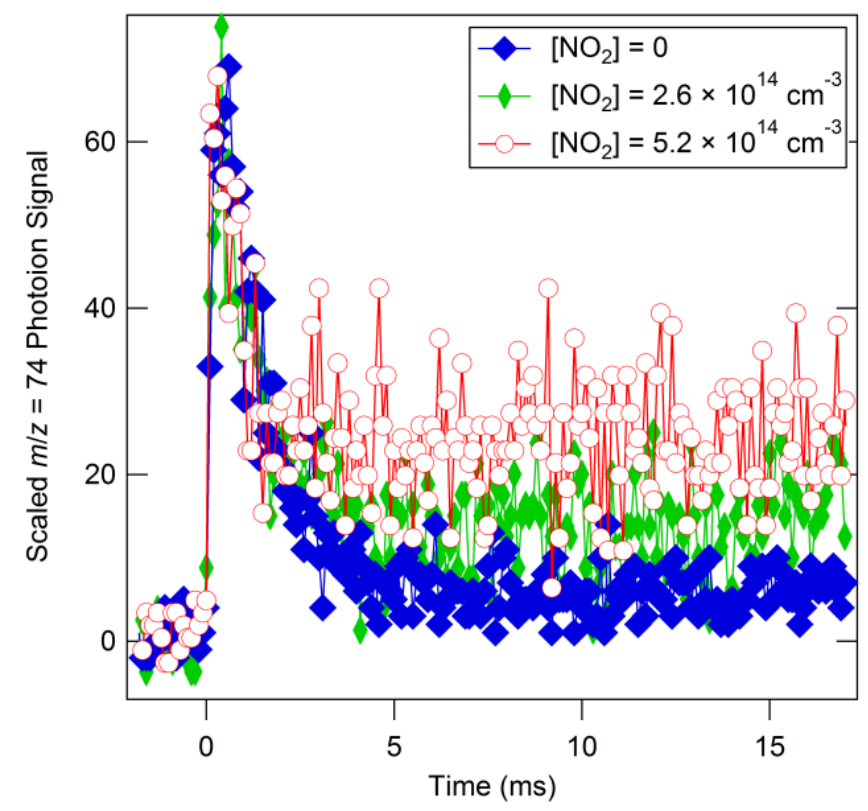

Figure 10. Time-resolved signal at $\mathrm{m} / \mathrm{z}=74$ (normalized at the peak) for different concentrations of $\mathrm{NO}_{2}$. The relative contribution of the persistent $\mathrm{m} / \mathrm{z}=74$ isomers increases with increasing $\left[\mathrm{NO}_{2}\right]$.

\section{$\mathrm{C}_{3} \mathrm{H}_{6} \mathrm{O}_{2}$ isomeric products from reactions of $\left(\mathrm{CH}_{3}\right)_{2} \mathrm{COO}$}

A small persistent signal at the mass of the Criegee intermediate is observed at long reaction times for all of the photoionization mass spectrometry experiments. Some of this signal can be attributed to hydroxyacetone, a product of unimolecular isomerization or self-reaction of $\left(\mathrm{CH}_{3}\right)_{2} \mathrm{COO}$, as discussed in more detail elsewhere. ${ }^{30}$ Reaction of $\left(\mathrm{CH}_{3}\right)_{2} \mathrm{COO}$ with $\mathrm{NO}_{2}$ or $\mathrm{SO}_{2}$ will compete with unimolecular isomerization or self-reaction, so addition of these reagents should reduce the contributions from these reactions. However, upon addition of $\mathrm{NO}_{2}$ the persistent isomer signal actually exhibited a substantial increase, as shown in Figure 10. The source of the increased persistent background is not completely clear, and may involve, for example a component of heterogeneous reaction of an association product. The photoionization spectra of the background in the presence and the absence of $\mathrm{NO}_{2}$ are shown in Figure 11. A similar change in the shape of the spectra is observed upon addition of $\mathrm{SO}_{2}$, although the change in amplitude of the persistent signal upon addition of $\mathrm{SO}_{2}$ was not consistent from experiment to experiment (which may support a role for heterogeneous reaction). Nevertheless, at least under some conditions the presence of $\mathrm{NO}_{2}$ or $\mathrm{SO}_{2}$ evidently serves to facilitate the isomerization of $\left(\mathrm{CH}_{3}\right)_{2} \mathrm{COO}$. 


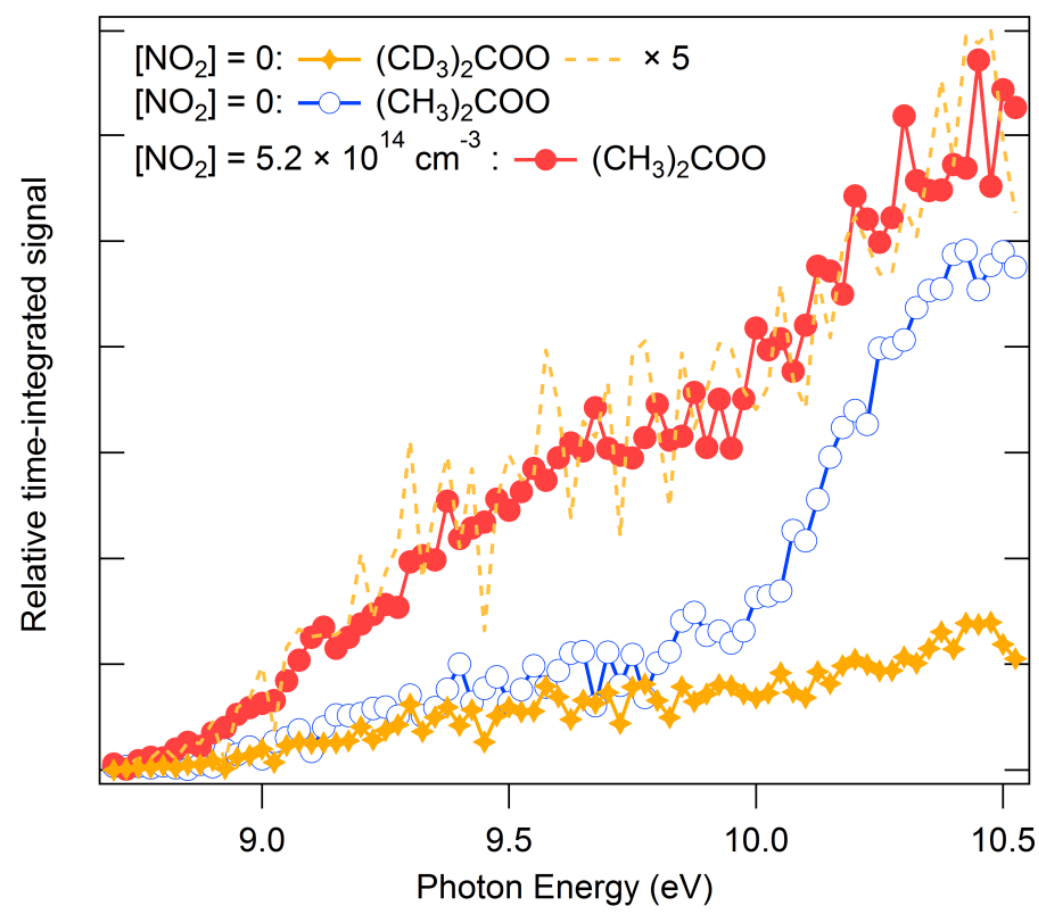

Figure 11. Photoionization spectra of the persistent $\mathrm{m} / \mathrm{z}=74$ signal in the presence and absence of $\mathrm{NO}_{2}$. The spectrum of the persistent $\mathrm{m} / \mathrm{z}=80$ signal from reaction of $\left(\mathrm{CD}_{3}\right)_{2} \mathrm{COO}$ is similar to the $\mathrm{m} / \mathrm{z}=74$ signal from the reactions of $\left(\mathrm{CH}_{3}\right)_{2} \mathrm{COO}$ in the presence of $\mathrm{NO}_{2}$

The spectrum without added reagent shows a prominent feature with an onset near $10 \mathrm{eV}$. This feature can be assigned to hydroxyacetone, based on comparison to authentic reference spectra. ${ }^{30}$ Addition of $\mathrm{NO}_{2}$ or $\mathrm{SO}_{2}$ reduced the contribution from hydroxyacetone, but increased the contributions of other long-lived $\mathrm{C}_{3} \mathrm{H}_{6} \mathrm{O}_{2}$ isomers. A similar change in the photoionization spectrum of the persistent $\mathrm{m} / \mathrm{z}=$ 74 signal was observed upon addition of $\mathrm{SO}_{2}$ but the increase in amplitude of the signal was generally small or negligible. For the perdeuterated reaction the persistent product signal is smaller and shows no increase with addition of $\mathrm{SO}_{2}$ or $\mathrm{NO}_{2}$. The hydroxyacetone feature is also absent in the perdeuterated reaction, suggesting a substantial normal kinetic isotope effect for the isomerization pathway that leads to hydroxyacetone.

Acetone oxide is known to isomerize to 2-hydroperoxypropene, as evidenced by the subsequent dissociation of the 2-hydroperoxypropene to form $\mathrm{OH}$ radical. ${ }^{29}$ The calculated photoionization onset and the near-threshold Franck-Condon envelope of 2-hydroperoxypropene are in reasonable agreement with the low-energy portion of the observed photoionization spectrum of the persistent $\mathrm{C}_{3} \mathrm{H}_{6} \mathrm{O}_{2}$ isomers. Other isomers, such as methyldioxetane, may also contribute; the photoionization spectra of the persistent isomers can be satisfactorily fit by a sum of hydroxyacetone and the calculated photoionization spectra of 2-hydroperoxypropene and methyldioxirane (see Figure 12). Because the absolute photoionization cross sections for 2-hydroperoxypropene and methyldioxirane are unknown, the yields cannot be quantified, but the relative change in the fractional contributions shows that hydroxyacetone is reduced and the contributions of 2-hydroperoxypropene and methyldioxirane both appear to increase upon addition of $\mathrm{NO}_{2}$ or $\mathrm{SO}_{2}$. 


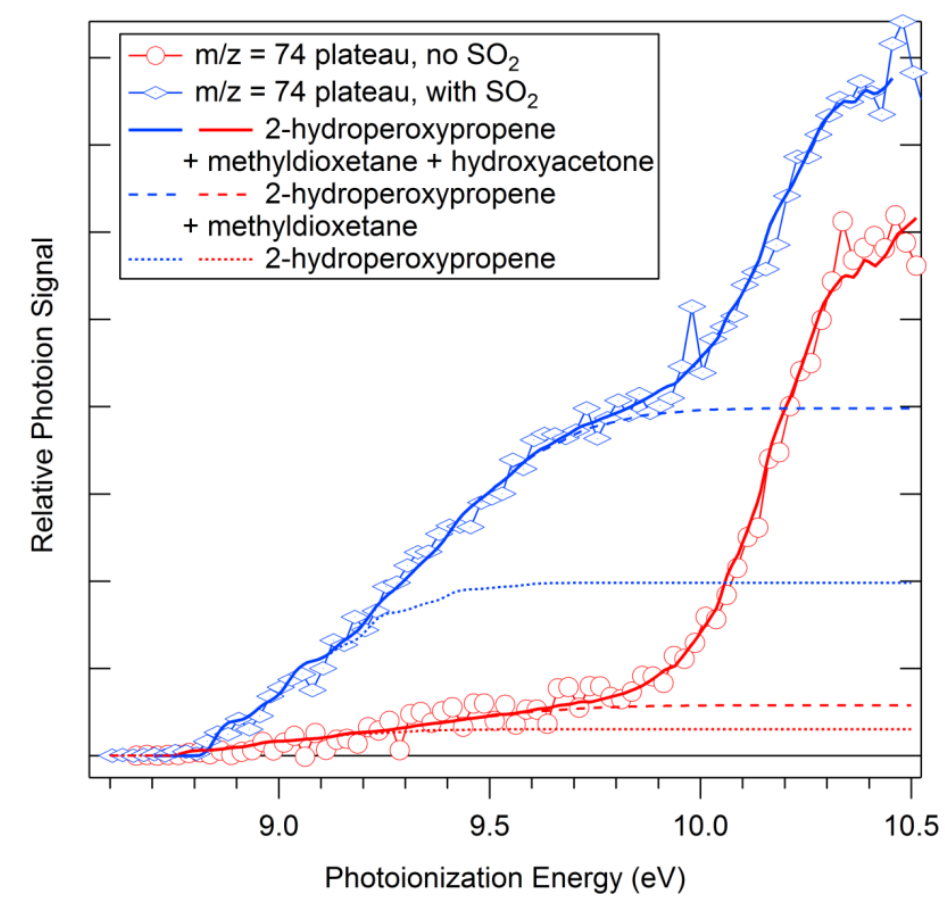

Figure 12. Photoionization spectrum of the persistent signal at $\mathrm{m} / \mathrm{z}=74$ in the presence and absence of added $\mathrm{SO}_{2}$. Also shown is a fit to the sum of predicted photoionization spectra of 2-hydroperoxypropene and methyldioxetane, and an experimental spectrum of hydroxyacetone.

\section{Conclusions}

Several reactions of the $\mathrm{C}_{3}$ Criegee intermediate acetone oxide have been characterized by photoionization mass spectrometry and cavity ring down methods. The self-reaction rate coefficient for acetone oxide is large, $(6.0 \pm 1.1) \times 10^{-10} \mathrm{~cm}^{3} \mathrm{~s}^{-1}$, following the trend of facile Criegee intermediate self-reaction noted for smaller carbonyl oxides. Deconvolution of the first-order and second-order components of the zero-reactant decay of $\left(\mathrm{CH}_{3}\right)_{2} \mathrm{COO}$ also permits an experimental estimate of its thermal unimolecular removal rate as $(305 \pm 70) \mathrm{s}^{-1}$. The measurements of bimolecular reactions kinetics confirm the rapid reaction of acetone oxide with $\mathrm{SO}_{2}$ and show a similar rate coefficient for reaction with $\mathrm{NO}_{2}$ as seen for other Criegee intermediates. Reaction with $\mathrm{NO}_{2}$ or with $\mathrm{SO}_{2}$ appears to facilitate isomerization of the acetone oxide under some conditions.

\section{Acknowledgements}

This material is based upon work supported by the Division of Chemical Sciences, Geosciences and Biosciences, Office of Basic Energy Sciences (BES), United States Department of Energy (USDOE). The Bristol group gratefully acknowledges financial support from the UK Natural Environment Research Council (NERC Grant NE/K004905/1). DKWM, JMD, CJP and EPFL are grateful to the Research Grant Council (RGC) of the Hong Kong Special Administrative Region (HKSAR, Grant Numbers PolyU 5011/12P) for support. Computations were carried out using resources of the National Service for Computational Chemistry Software (NSCCS), EPSRC (UK), and the IRIDIS High Performance Computing Facility, the University of Southampton. We thank Adam M. Scheer, Kendrew $\mathrm{Au}$, and Howard Johnsen for assistance with the experiments at Sandia and the Advanced Light Source, and Darryl Y. Sasaki for help with synthesis of 2,2-diiodopropane. Sandia National Laboratories is a multiprogram laboratory operated by Sandia Corporation, a Lockheed Martin Company, for the USDOE's National Nuclear Security Administration under contract DEAC0494AL85000. This research used resources of the Advanced Light Source of Lawrence Berkeley National Laboratory, which is a USDOE Office of Science User Facility. The Advanced Light Source 
is supported by the Director, Office of Science, BES/USDOE, under contract DE-AC02-05CH11231 between Lawrence Berkeley National Laboratory and the USDOE.

\section{References}

1. Criegee, R., Mechanism of Ozonolysis. Angew. Chem. Internat. Edit. 1975, 14 (11), 745-752.

2. Donahue, N. M.; Drozd, G. T.; Epstein, S. A.; Presto, A. A.; Kroll, J. H., Adventures in ozoneland: down the rabbit-hole. Phys. Chem. Chem. Phys. 2011, 13, 10848-10857.

3. Johnson, D.; Marston, G., The gas-phase ozonolysis of unsaturated volatile organic compounds in the troposphere. Chem. Soc. Rev. 2008, 37 (4), 699-716.

4. Osborn, D. L.; Taatjes, C. A., The physical chemistry of Criegee intermediates in the gas phase. International Reviews in Physical Chemistry 2015, 34 (3), 309-360.

5. Lee, Y.-P., Perspective: Spectroscopy and kinetics of small gaseous Criegee intermediates. J. Chem. Phys. 2015, 143, 020901.

6. Taatjes, C. A.; Shallcross, D. E.; Percival, C. J., Research frontiers in the chemistry of Criegee intermediates and tropospheric ozonolysis. Phys. Chem. Chem. Phys. 2014, 16 1704-1718.

7. Welz, O.; Savee, J. D.; Osborn, D. L.; Vasu, S. S.; Percival, C. J.; Shallcross, D. E.; Taatjes, C. A., Direct Kinetic Measurements of Criegee Intermediate $\left(\mathrm{CH}_{2} \mathrm{OO}\right)$ Formed by Reaction of $\mathrm{CH}_{2} \mathrm{I}$ with $\mathrm{O}_{2}$. Science 2012, 335, 204-207.

8. Taatjes, C. A.; Welz, O.; Eskola, A. J.; Savee, J. D.; Scheer, A. M.; Shallcross, D. E.; Rotavera, B.; Lee, E. P. F.; Dyke, J. M.; Mok, D. K. W.; Osborn, D. L.; Percival, C. J., Direct Measurements of Conformer-Dependent Reactivity of the Criegee Intermediate $\mathrm{CH}_{3} \mathrm{CHOO}$. Science 2013, 340 (6129), 171-180.

9. Buras, Z. J.; Elsamra, R. M. I.; Green, W. H., Direct Determination of the Simplest Criegee Intermediate (CH2OO) Self Reaction Rate. J. Phys. Chem. Lett 2014, 5, 2224-2228.

10. Su, Y.-T.; Lin, H.-Y.; Putikam, R.; Matsui, H.; Lin, M. C.; Lee, Y.-P., Extremely rapid self-reaction of the simplest Criegee intermediate $\mathrm{CH}_{2} \mathrm{OO}$ and its implications in atmospheric chemistry. Nature Chemistry 2014.

11. Chhantyal-Pun, R.; Davey, A.; Shallcross, D. E.; Percival, C. J.; Orr-Ewing, A. J., A kinetic study of the $\mathrm{CH} 2 \mathrm{OO}$ Criegee intermediate self-reaction, reaction with $\mathrm{SO} 2$ and unimolecular reaction using cavity ring-down spectroscopy. Phys. Chem. Chem. Phys. 2015, 17, 3617-3626.

12. Huang, H.-L.; Chao, W.; Lin, J. J.-M., Kinetics of a Criegee intermediate that would survive high humidity and may oxidize atmospheric $\mathrm{SO}_{2}$. Proc. Nat. Acad. Sci. 2015, 112 (35), 10857-10862.

13. Newland, M. J.; Rickard, A. R.; Alam, M. S.; Vereecken, L.; Muñoz, A.; Ródenas, M.; Bloss, W. J., Kinetics of stabilised Criegee intermediates derived from alkene ozonolysis: reactions with SO 2, H $2 \mathrm{O}$ and decomposition under boundary layer conditions. Physical Chemistry Chemical Physics 2015, 17 (6), 4076-4088.

14. Stone, D.; Blitz, M.; Daubney, L.; Howes, N. U. M.; Seakins, P., Kinetics of $\mathrm{CH}_{2} \mathrm{OO}$ reactions with $\mathrm{SO}_{2}, \mathrm{NO}_{2}, \mathrm{NO}, \mathrm{H}_{2} \mathrm{O}$ and $\mathrm{CH}_{3} \mathrm{CHO}$ as a function of pressure. Phys. Chem. Chem. Phys. 2014, 16 (3), 1139-1149.

15. Vereecken, L.; Harder, H.; Novelli, A., The reaction of Criegee intermediates with NO, RO2, and SO2, and their fate in the atmosphere. Phys. Chem. Chem. Phys. 2012, 14 (42), 14682-14695.

16. Sipilä, M.; Jokinen, T.; Berndt, T.; Richters, S.; Makkonen, R.; Donahue, N. M.; Mauldin III, R. L.; Kurten, T.; Paasonen, P.; Sarnela, N.; Ehn, M.; Junninen, H.; Rissanen, M. P.; Thornton, J.; 
Stratmann, F.; Herrmann, H.; Worsnop, D. R.; Kulmala, M.; Kerminen, V.-M.; Petäjä, T., Reactivity of stabilized Criegee intermediates $(\mathrm{sCl})$ from isoprene and monoterpene ozonolysis toward $\mathrm{SO}_{2}$ and organic acids. Atmos. Chem. Phys. 2014, 14, 12143-12153.

17. Welz, O.; Eskola, A. J.; Sheps, L.; Rotavera, B.; Savee, J. D.; Scheer, A. M.; Osborn, D. L.; Lowe, D.; Booth, A. M.; Xiao, P.; Khan, M. A. H.; Percival, C. J.; Shallcross, D. E.; Taatjes, C. A., Rate Coefficients of $\mathrm{C} 1$ and $\mathrm{C} 2$ Criegee Intermediate Reactions with Formic and Acetic Acid Near the Collision Limit: Direct Kinetics Measurements and Atmospheric Implications. Angew. Chem. Int. Ed. 2014.

18. Foreman, E. S.; Kapnas, K. M.; Murray, C., Reactions between Criegee Intermediates and the Inorganic Acids $\mathrm{HCl}$ and $\mathrm{HNO}_{3}$ : Kinetics and Atmospheric Implications. Angew. Chem. Int. Ed. 2016, in press, doi:10.1002/anie.201604662.

19. Ouyang, B.; McLeod, M. W.; Jones, R. L.; Bloss, W. J., NO3 radical production from the reaction between the Criegee intermediate $\mathrm{CH} 2 \mathrm{OO}$ and NO2 Phys. Chem. Chem. Phys. 2013, 15 (40), 17070-17075.

20. Sheps, L.; Scully, A. M.; Au, K., UV absorption probing of the conformer-dependent reactivity of a Criegee intermediate $\mathrm{CH}_{3} \mathrm{CHOO}$. Phys. Chem. Chem. Phys. 2014, 16, 26701-26706.

21. Okumura, M., Just add water dimers. Science 2015, 347 (6223), 718-719.

22. Liu, F.; Beames, J. M.; Green, A. M.; Lester, M. I., UV Spectroscopic Characterization of Dimethyl- and Ethyl-Substituted Carbonyl Oxides. J. Phys. Chem. A 2014, 118, 2298-2306.

23. Frisch, M. J.; Trucks, G. W.; Schlegel, H. B.; Scuseria, G. E.; Robb, M. A.; Cheeseman, J. R.; Scalmani, G.; Barone, V.; Mennucci, B.; Petersson, G. A.; Nakatsuji, H.; Caricato, M.; Li, X.; Hratchian, H. P.; Izmaylov, A. F.; Bloino, J.; Zheng, G.; Sonnenberg, J. L.; Hada, M.; Ehara, M.; Toyota, K.; Fukuda, R.; Hasegawa, J.; Ishida, M.; Nakajima, T.; Honda, Y.; Kitao, O.; Nakai, H.; Vreven, T.; Montgomery, J., J. A.; Peralta, J. E.; Ogliaro, F.; Bearpark, M.; Heyd, J. J.; Brothers, E.; Kudin, K. N.; Staroverov, V. N.; Kobayashi, R.; Normand, J.; Raghavachari, K.; Rendell, A.; Burant, J. C.; Iyengar, S. S.; Tomasi, J.; Cossi, M.; Rega, N.; Millam, N. J.; Klene, M.; Knox, J. E.; Cross, J. B.; Bakken, V.; Adamo, C.; Jaramillo, J.; Gomperts, R.; Stratmann, R. E.; Yazyev, O.; Austin, A. J.; Cammi, R.; Pomelli, C.; Ochterski, J. W.; Martin, R. L.; Morokuma, K.; Zakrzewski, V. G.; Voth, G. A.; Salvador, P.; Dannenberg, J. J.; Dapprich, S.; Daniels, A. D.; Farkas, Ö.; Foresman, J. B.; Ortiz, J. V.; Cioslowski, J.; Fox, D. J. Gaussian 09, Revision A.02, Gaussian, Inc.: Wallingford CT, 2009.

24. Werner, H.-J.; Knowles, P. J.; Manby, F. R.; Schütz, M.; Celani, P.; Knizia, G.; Korona, T.; Lindh, R.; Mitrushenkov, A.; Rauhut, G.; Adler, T. B.; Amos, R. D.; Bernhardsson, A.; Berning, A.; Cooper, D.

L.; Deegan, M. J. O.; Dobbyn, A. J.; Eckert, F.; Goll, E.; Hampel, C.; Hesselmann, A.; Hetzer, G.; Hrenar, T.; Jansen, G.; Köppl, C.; Liu, Y.; Lloyd, A. W.; Mata, R. A.; May, A. J.; McNicholas, S. J.; Meyer, W.; Mura, M. E.; Nicklass, A.; Palmieri, P.; Pflüger, K.; Pitzer, R.; Reiher, M.; Shiozaki, T.; Stoll, H.; Stone, A. J.; Tarroni, R.; Thorsteinsson, T.; Wang, M.; Wolf, A. MOLPRO, version 2012.1, a package of ab initio programs (see http://www.molpro.net). 2012.

25. Mozhayskiy, V. A.; Krylov, A. I. ezSpectrum.

26. Peterson, K. A.; Shepler, B. C.; Figgen, D.; Stoll, H., On the Spectroscopic and Thermochemical Properties of $\mathrm{ClO}, \mathrm{BrO}, \mathrm{OO}$, and Their Anions. J. Phys. Chem. A 2006, 110 (51), 13877-13883.

27. Xu, X.; Alecu, I. M.; Truhlar, D. G., How Well Can Modern Density Functionals Predict Internuclear Distances at Transition States? J. Chem. Theory Comput. 2011, 7 (6), 1667-1676.

28. Lee, E. P. F.; Mok, D. K. W.; Shallcross, D. E.; Percival, C. J.; Osborn, D. L.; Taatjes, C. A.; Dyke, J. M., Spectroscopy of the Simplest Criegee Intermediate CH2OO: Simulation of the First Bands in Its Electronic and Photoelectron Spectra. Chem.-Eur. J. 2012, 18 (39), 12411-12423.

29. Liu, F.; Beames, J. M.; Lester, M. I., Direct production of $\mathrm{OH}$ radicals upon $\mathrm{CH}$ overtone activation of (CH3)(2)COO Criegee intermediates. J. Chem. Phys. 2014, 141 (23), 234312.

30. Taatjes, C. A.; Liu, F.; Rotavera, B.; Kumar, M.; Caravan, R.; Osborn, D. L.; Thompson, W. H.; Lester, M. I., Hydroxyacetone production from C3 Criegee intermediates. J. Phys. Chem. A 2016, companion paper. 
31. Fang, Y.; Liu, F.; Barber, V. P.; Klippenstein, S. J.; McCoy, A. B.; Lester, M. I., Communication: Real time observation of unimolecular decay of Criegee intermediates to $\mathrm{OH}$ radical products. J.

Chem. Phys. 2016, 144, 061102.

32. Olzmann, M.; Kraka, E.; Cremer, D.; Gutbrod, R.; Andersson, S., Energetics, Kinetics, and Product Distributions of the Reactions of Ozone with Ethene and 2,3-Dimethyl-2-butene. J. Phys. Chem. A 1997, 101, 9421-9429.

33. Huang, H.; Rotavera, B.; Eskola, A. J.; Taatjes, C. A., Pressure-Dependent I Atom Yield in the Reaction of CH2I with O-2 Shows a Remarkable Apparent Third-Body Efficiency for O-2 (vol 3, pg 3399, 2012). J. Phys. Chem. Lett. 2013, 4 (22), 3824-3824.

34. Huang, H.; Eskola, A. J.; Taatjes, C. A., Pressure-Dependent I-Atom Yield in the Reaction of $\mathrm{CH} 2 \mathrm{I}$ with O-2 Shows a Remarkable Apparent Third-Body Efficiency for O-2. J. Phys. Chem. Lett. 2012, 3 (22), 3399-3403.

35. Stone, D.; Blitz, M.; Daubney, L.; Ingham, T.; Seakins, P., $\mathrm{CH}_{2} \mathrm{OO}$ Criegee Biradical Yields Following Photolysis of $\mathrm{CH}_{2} \mathrm{I}_{2}$ in $\mathrm{O}_{2}$. Phys. Chem. Chem. Phys. 2013, 15 (44), 19119-19124.

36. Levine, R. D., Molecular Reaction Dynamics. Cambridge University Press: 2009.

37. Anglada, J. M.; Gonzalez, J.; Torrent-Sucarrat, M., Effects of the substituents on the reactivity of carbonyl oxides. A theoretical study on the reaction of substituted carbonyl oxides with water. Phys. Chem. Chem. Phys. 2011, 13 13034-13045.

38. Presto, A. A.; Donahue, N. M., Ozonolysis Fragment Quenching by Nitrate Formation: The Pressure Dependence of Prompt OH Radical Formation. J. Phys. Chem. A 2004, 108, 9096-9104. 